\title{
Structure and Chemical Composition of Different Variants of a Commercial Trivalent Chromium Process (TCP) Coating on Aluminum Alloy 7075-T6
}

\author{
Catherine A. Munson and Greg M. Swain* \\ *Department of Chemistry, Michigan State University, East Lansing, \\ MI 48824-1322
}

\begin{abstract}
$\underline{\text { Abstract }}$
The structure and chemical composition of different variants of a commercial (SurTec 650 chromitAL) trivalent chromium process (TCP) conversion coating formed on AA7075-T6 are reported on. Comparison of coatings formed by immersion and spray was undertaken. Three different variants of the TCP coating were studied: $650 \mathrm{E}, \mathrm{C}$ and V. ICP-OES revealed similar concentrations of $\mathrm{Cr}$ in all three coating baths but differences in $\mathrm{Zr}, \mathrm{Zn}, \mathrm{S}$ (likely as sulfate), and Fe among the three. SEM and EDXS analysis revealed the coating forms (immersion and spray) over the entire alloy surface with some enrichment or thickening on and around intermetallic particles. The coatings generally consist of nodular particles (aggregates) that decorate the surface of all three coatings with the greatest number density seen for 650 E. Cracking and delamination were seen only for $650 \mathrm{C}$ applied by immersion. The conversion coatings (immersion or spray) become more hydrophobic over a 7-day aging period in the laboratory air. Static water contact angles at day 7 are $60-90^{\circ}$ for all the coatings. Ellipsometry data indicated $650 \mathrm{E}$ is the thickest of the three coatings at $95 \mathrm{~nm}$ after a 7-day aging period in the laboratory air. Overall, the thickness of the spray-coated films $(3 \mathrm{~min})$ is less than the immersion-coated
\end{abstract}


films (4 min). Finally, Raman spectroscopy confirmed the presence of localized regions of $\mathrm{Cr}(\mathrm{III})-\mathrm{O}$ species (e.g., $\mathrm{Cr}(\mathrm{OH})_{3}$ ) in the coatings with co-localized and transiently-formed $\mathrm{Cr}(\mathrm{VI})-\mathrm{O}$ species (e.g., $\mathrm{CrO}_{4}{ }^{2-}$ and or $\mathrm{HCrO}_{4}{ }^{-}$).

Key words: trivalent chromium process coating, aluminum alloy, chemical composition, physical structure 


\section{Introduction}

Multi-layer coating systems (conversion coating + primer + topcoat) are used to protect aerospace aluminum alloys from corrosion in service. Traditional coating systems contain hexavalent chromium $(\mathrm{Cr}(\mathrm{VI}))$ in both the conversion coating and primer, volatile organic compounds (VOC) and hazardous air pollutants (HAP) in both the primer and topcoat, as well as several heavy metals used for corrosion protection and color. ${ }^{1}$ Environmental and health concerns are driving the aerospace industry to transition away from the chromated conversion coatings and primers to more environmentally-friendly coating systems. ${ }^{1-3}$ Conversion coatings are thin, hydrated metal oxide films formed on a metal surface that ideally provide adhesion promotion with primers, anti-corrosion properties to the base metal, and a reservoir of inhibitor ions during the coating lifetime. ${ }^{4-6}$ To this end, the Naval Air Systems Command (NAVAIR) has formulated some novel coating chemistries for metal finishing and developed associated application processes. Two of these for aluminum alloys are (i) non-chromated process (NCP) and (ii) trivalent chromium process (TCP) conversion coatings. NCP is a non-chromium, zirconium and zinc-based aqueous coating that can be applied by both immersion and spray. ${ }^{7,8}$ TCP is a non-chromated, trivalent chromium and zirconium-based coating that can also be applied by immersion or spray. ${ }^{9,10}$ Both have undergone field testing on some assets, however, much remains to be learned about the mechanism(s) by which these coatings inhibit corrosion on different alloys in a variety of test environments, and how combinations of these non-chromated conversion coatings with primers maintain high corrosion resistance and good physical properties. 
TCP is the leading candidate to replace the chromated pretreatment conversion coatings on aerospace aluminum alloys. ${ }^{9-21}$ TCP has been licensed by several vendors and is currently marketed under different names: Bonderite M-Cr T5900 from Henkel, TCP-HF from Chemeon (formerly Metalast), 650 ChromitAL from SurTec and Aluminescent from Luster-on. These coating baths have chemical compositions that differ to some extent from the original NAVAIR formulation so, from a research perspective, each should be treated as a separate coating system. Generally speaking, while these commercial TCP coatings have been qualified for use in selected applications, differences are often observed in their anti-corrosion properties on aluminum alloys, particularly during accelerated corrosion testing and environmental exposure. The morphology and chemical composition of a TCP coating, and therefore the anti-corrosion properties, will depend on the coating bath composition, the cleanliness of the alloy surface, the chemical composition of the alloy surface namely the number density of intermetallic phases present, and the alloy surface morphology (i.e., pit size and density). Improvements in the TCP coating's anti-corrosion performance could be realized with more fundamental knowledge regarding the physical structure and chemical composition of the coating, how the coating structure depends on the surface pretreatment of the alloy and the corrosion inhibition mechanism(s).

There has been limited published work to date on fundamental investigations of the TCP coating formation mechanism, the physical and chemical structure of the coating on different aluminum alloys, and correlation of these properties with the anti-corrosion behavior. We have reported such data for the Bonderite M-Cr T5900 coating from Henkel on AA2024-T3, AA6061- 
T6 and AA7075-T6. ${ }^{12,15-18}$ There have also been some reports on the 650 ChromitAl from SurTec. $^{19-23}$

In this paper, we report on a systematic study of three versions of the SurTec TCP coating (650 E, V and C) applied to degreased and deoxidized AA7075-T6 by immersion and spray. The inorganic content in the coating baths was quantified by ICP-OES. The coating morphology and chemical composition were assessed by SEM and EDXS analysis, respectively. The elemental composition through the coating was determined by depth-profiling AES. The presence of $\mathrm{Cr}(\mathrm{III})-\mathrm{O}$ and $\mathrm{Cr}(\mathrm{VI})-\mathrm{O}$ vibrational modes in the coating was verified by Raman spectroscopy. Finally, the coating thickness was measured by ellipsometry (in air) and the coating wettability was assessed by static water contact angle measurements. We sought to answer two key questions:

1) What are the chemical composition differences in the coating baths and do these compositional differences lead to coatings with different structure and composition?

2) Are the physical structure and chemical composition of the coatings different for immersion versus spray-on application?

Correlating the anti-corrosion properties of the coatings with their physical and chemical structure was also addressed during the work. These results will be reported in a separate publication. 


\section{Material and Methods}

\subsection{Reagents}

The 133 degreaser and 495L deoxidizer (SurTec, Inc., Brunswick, OH) were prepared to 4 wt. \% and 20 vol. \%, respectively. The $650 \mathrm{E}$ (also known as the traditional chromitAl 650), $\mathrm{V}$, and C TCP coating baths were prepared to 20 vol. $\%$. The $\mathrm{pH}$ of the coating solution was adjusted to 3.85 using $0.1 \mathrm{M} \mathrm{NaOH}$ or $0.1 \mathrm{M} \mathrm{H}_{2} \mathrm{SO}_{4}$, as needed. All solutions were prepared using ultrapure water (Barnstead E-Pure) with a resistivity $>17 \mathrm{M} \Omega \cdot \mathrm{cm}$.

\subsection{Specimen Preparation}

The AA7075-T6 was obtained as a 2-mm thick sheet (www.onlinemetals.com), which was cut into $1 \mathrm{~cm}^{2}$ specimens. The composition of the alloy was determined by $\mathrm{x}$-ray fluorescence (XRF) using known sensitivity factors for the different elements. The measurements were made by energy dispersive x-ray fluorescence (Bruker S2 Ranger). The quantitative results are presented in Table 1 . All values are within the expected range ${ }^{24}$, except for $\mathrm{Mg}$ which is a little higher than expected for this alloy.

Table 1. The elemental composition (wt.\%) of AA7075-T6 as determined from quantitative XRF analysis.

\begin{tabular}{cccc} 
Elemental Composition (wt. \%) & & $\underline{\text { XRF }}$ & Expected Range \\
\cline { 1 - 3 } $\mathrm{Cu}$ & & $1.61 \pm 0.02$ & $1.2-2$ \\
$\mathrm{Fe}$ & $0.25 \pm 0.01$ & $<0.5$ \\
$\mathrm{Mg}$ & $6.00 \pm 0.06$ & $2.1-2.9$ \\
$\mathrm{Mn}$ & $\mathrm{ND}$ & $<0.3$ \\
$\mathrm{Si}$ & $0.33 \pm 0.03$ & $<0.4$ \\
$\mathrm{Zn}$ & $5.71 \pm 0.06$ & $5.1-6.1$ \\
$\mathrm{Ti}$ & $0.04 \pm 0.01$ & $<0.2$ \\
$\mathrm{Cr}$ & $0.22 \pm 0.01$ & $0.18-0.28$ \\
$\mathrm{Al}$ & $84.75 \pm 0.27$ & $87.1-91.4$
\end{tabular}

Values are reported as mean \pm standard error of the mean for $\mathrm{n}=3$ specimens. Known values are from the ASM material data sheet for AA7075-T6. ${ }^{24} \mathrm{ND}=$ not detected. Total mass balance $=98.91 \%$. 
The specimens were prepared for conversion coating by first wet sanding for 4 min using 1500 grit aluminum oxide paper to smooth the surface and to expose fresh alloy. This was followed by ultrasonic cleaning for $20 \mathrm{~min}$ in ultrapure water in a covered glass beaker. The specimens were then hand polished for 4 min using a $0.3-\mu \mathrm{m}$ diameter alumina powder (Buehler) slurry on a felt polishing pad. The alumina slurry or paste was prepared by mixing the powder with ultrapure water directly on the polishing pad. The polished specimens were then ultrasonically cleaned for $20 \mathrm{~min}$ in ultrapure water in a covered glass beaker. After polishing, the specimens were degreased by a 5 -min immersion in 4 wt. \% SurTec 133 at $60^{\circ} \mathrm{C}$ in a glass beaker. This is an alkaline $(\mathrm{pH}$ 9.0-9.5) and silicate-free degreaser that contains phosphate and borate surfactants. The specimens were gently agitated each minute of the cleaning. The specimens were then rinsed for 2 min under gently flowing city tap water, which contained $\sim 0.1 \mathrm{ppm} \mathrm{Zr}$, $\sim 0.2 \mathrm{ppm} \mathrm{Cu}, \mathrm{Fe}, \mathrm{Zn}, \sim 0.4 \mathrm{ppm} \mathrm{Al}$, and 30-45 ppm Ca, $\mathrm{Mg}$, and $\mathrm{S}$ as determined using ICP-OES (Figure 1). This was followed by

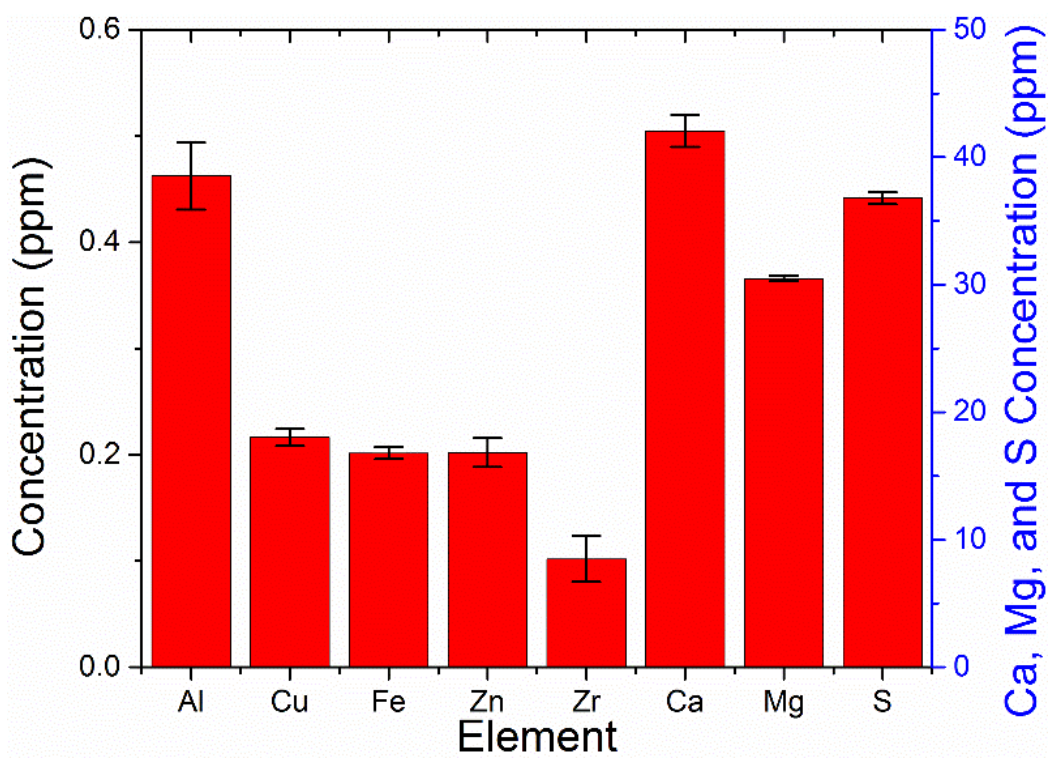

Figure 1. Elemental analysis of the city tap water (July 2016) used for specimen rinsing as determined by ICP-OES. Data are presented as mean \pm S.E.M. for $n \geq 3$. 
deoxidation for $2 \mathrm{~min}$ in $20 \mathrm{vol}$ \% SurTec $495 \mathrm{~L}$ at room temperature. The deoxidation was performed in a glass beaker without any specimen agitation. This fluoride-containing deoxidizer has a sulfuric acid base with added Fe salts. The specimens were then rinsed for 2 min under gently flowing city tap water. At this point, the pretreated specimens were dried under a stream of nitrogen and stored in a petri dish until further use. These specimens are referred to as "uncoated". 
The TCP coating was applied to degreased and deoxidized specimens by immersion or spray. Immersion-coated specimens were placed in a 20 vol. $\% 650 \mathrm{E}, \mathrm{C}$, or V solution at $30^{\circ} \mathrm{C}$ for 4 min without any agitation. Spray-coated specimens were sprayed every $30 \mathrm{~s}$ for a 3 -min period at room temperature, $\sim 21-25^{\circ} \mathrm{C}$. These coating conditions were selected based on recommendations by the supplier. The spray coating was applied with a nebulizing spray bottle. The immersion-coated specimens were then rinsed by immersion in city tap water for $2 \mathrm{~min}$ followed by a final soak in ultrapure water for $30 \mathrm{~s}$. The spray-coated specimens were then rinsed with a city tap water spray every $30 \mathrm{~s}$ for a 2 -min period followed by a final immersion in

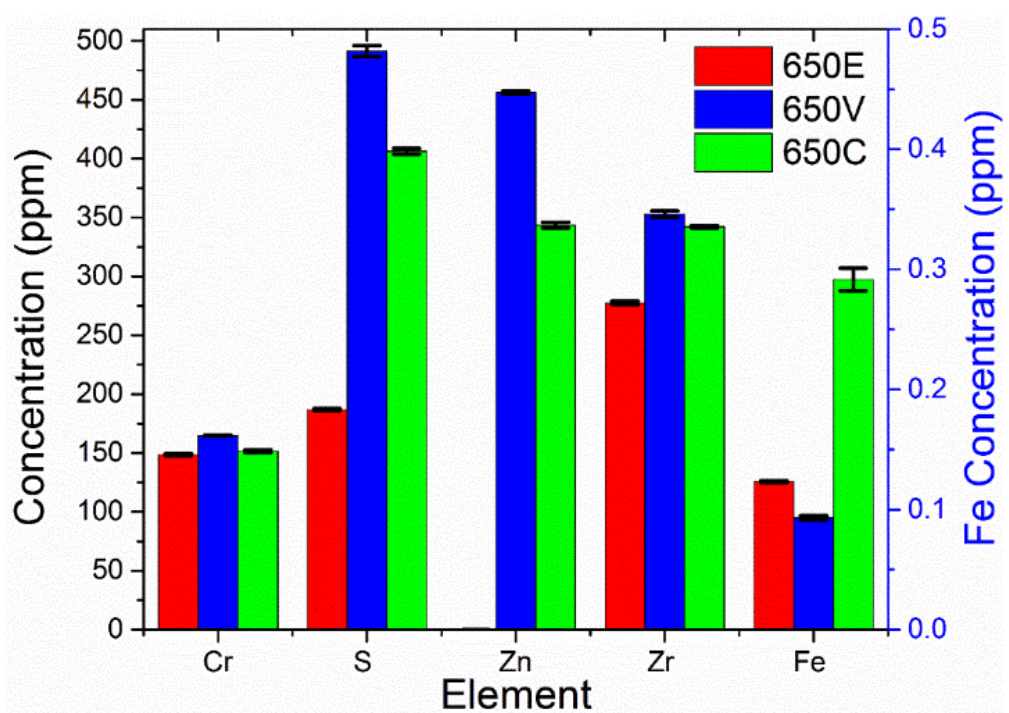

ultrapure water for $30 \mathrm{~s}$. The coated specimens were allowed to dry in the laboratory atmosphere overnight before further testing. The drying or aging was performed at room temperature in a covered petri dish.

Figure 2. Elemental analysis of SurTec $650 \mathrm{E}$ (red), $650 \mathrm{~V}$ (blue), and $650 \mathrm{C}$ (green) coating baths as determined by ICP-OES analysis. Data are presented as mean \pm S.E.M. for $\mathrm{n} \geq 3$.

Quantitative inorganic chemical analysis of the city tap water and the coating baths was performed on a Varian 710-ES ICP-OES. Quantitation was performed using response curves generated with external standards. The results for the coating bath composition are presented in 
Figure 2. The major chemical differences in the coatings are $\mathrm{Zn}$ in $650 \mathrm{~V}$ and $\mathrm{C}$, the greater level of $\mathrm{S}$ in $650 \mathrm{~V}$ and $\mathrm{C}$, and the greater level of $\mathrm{Fe}$ in $650 \mathrm{C}$. The $\mathrm{Zr} / \mathrm{Cr}$ ratio is approximately 2:1 for all three coating variants. SurTec $650(650 \mathrm{E})$ is the first-generation of the coating based on the original NAVAIR formulation with $\mathrm{Zr}^{+4}$ and $\mathrm{Cr}^{+3}$ salts. $650 \mathrm{~V}$ is the second-generation of the coating with the same general composition as $650 \mathrm{E}$ plus some added complexing agents. $650 \mathrm{~V}$ is designed to produce a heavier coating than $650 \mathrm{E}$ with more coloration for visible detection. $650 \mathrm{C}$ is generally similar to $650 \mathrm{~V}$ in chemical composition, with some different complexing agents added. During the course of this work, it was learned that the $650 \mathrm{C}$ has been discontinued from the company's product line.

\subsection{Alloy and Coating Characterization}

Scanning electron microscopy and energy dispersive x-ray analysis (EDXS) were performed using a field emission SEM (JEOL 7500F) with an energy dispersive x-ray microanalysis attachment. These studies were performed to assess the metallographic condition of the pretreated and coated specimen surfaces. The X-ray emission lines from EDXS spectra were used to determine the presence of the conversion coating $(\mathrm{Zr}, \mathrm{Cr}, \mathrm{F}$ and $\mathrm{O}$ ) near intermetallic particles and away from these particles on the aluminum matrix. The measurements were made at the Center for Advanced Microscopy (MSU). Raman microprobe spectroscopy was performed using a Renishaw inVia Confocal Raman Microscope equipped with a Nd:YAG laser (45 W maximum power with $10 \%$ of this used at the specimen surface). The excitation line was at $523 \mathrm{~nm}$. Raman spectroscopy was used principally to probe the coatings for the presence of $\mathrm{Cr}^{+3}-\mathrm{O}\left(\mathrm{Cr}(\mathrm{OH})_{3}\right)$ and $\mathrm{Cr}^{+6}-\mathrm{O}\left(\mathrm{CrO}_{4}{ }^{2-}\right.$ or $\left.\mathrm{HCrO}_{4}^{-}\right)$vibrational modes in the coating. Ellipsometry (in air) was performed using a VASE ellipsometer with a $75 \mathrm{~W}$ Xenon light source to determine the coating thickness. Static water contact angles were measured with an AST 
Products Video Contact Angle System 2000 with a 150 W light source to determine the coating wettability. Surface profilometry was performed on a NanoMap-500LS Contact Surface Profilometer at the Electrical and Computer Engineering Testing Facility (MSU). The surface profilometry provided information on the specimen surface roughness, pit density, and pit dimensions.

\section{Calculations and Statistical Analysis}

Spectroscopic ellipsometry measures the change in polarization state of linearly polarized light upon reflection from a surface. The measured ellipsometry parameters are the amplitude ratio $(\tan \Psi)$ and the phase shift difference $(\Delta)$ of the parallel and perpendicularly polarized components of the reflected light $\left(r_{s}\right.$ and $\left.r_{p}\right)$. The parameters are defined through the expression, $\tan (\Psi) \exp (\Delta)=\mathrm{r}_{\mathrm{p}} / \mathrm{r}_{\mathrm{s}}$. These measured responses depend on the optical properties (e.g., refractive index, n) and coating thickness, $\mathrm{d}$. Using model analysis and an iterative process, $\mathrm{n}$ and $\mathrm{d}$ are determined indirectly by calculating $\Psi$ and $\Delta$ from known values of $\mathrm{n}$ and $\mathrm{d}$ until the calculated values of $\Psi$ and $\Delta$ match the experimental values. $\tan (\Psi)$ and $\exp (\Delta)$ are calculated using Fresnel equations. ${ }^{18,25,26}$ Calculations of coating thickness, the phase and amplitude were fit to a Cauchy model to determine the refractive index (n) of the film: $n=A+B / \lambda^{2}+C / \lambda^{4}$, where $\lambda$ is the wavelength of incident light, and A, B, and C are the fitting parameters. ${ }^{18,25,26}$ To calculate $\mathrm{n}, 600 \mathrm{~nm}$ was chosen as the wavelength, A, B, and C were determined from the experimental fit, and $\mathrm{n}$ was calculated according to the following equation:

$$
\mathrm{n}=\mathrm{A}+\frac{B}{\lambda^{2}}+\frac{C}{\lambda^{4}}
$$

The nominal $\mathrm{n}$ value was $2.38 \pm 0.13$ for all film compositions, similar to those calculated

for this coating as well as a different brand (Bonderite T5900) of TCP. ${ }^{18,25,26}$ Using the Cauchy 
model and an initial proposed film thickness, a computer algorithm adjusts the parameters (A, B, $\mathrm{C}$, and $\mathrm{d}=$ film thickness) until the lowest mean squared error is attained.

Any statistical differences reported were determined using the two-specimen t-test with a significance level of 0.05 . All values are displayed as a mean \pm the standard error of the mean for at least 3 specimens and graphed as the mean with error bars.

\section{Results}

\subsection{Elemental composition of the different coating baths}

The TCP coating baths have different chemical compositions as determined by ICP-OES analysis. The results are presented in Figure 2. The analysis was performed on the as-received coating bath solutions that were first diluted to 20 vol. \% with ultrapure water followed by a second dilution to 10 vol. \% with $0.48 \mathrm{M} \mathrm{HNO}_{3}$. Quantitation was performed using external standards of each element prepared in the $0.48 \mathrm{M} \mathrm{HNO}_{3}$. The results in Figure 2 represent the elemental concentrations in the 20 vol. \% baths used for all coating applications. The $\mathrm{Cr}$ concentration is similar for all three coating baths at $\sim 150 \mathrm{ppm}$. The nominal $\mathrm{Zr}$ concentration in all three baths is higher than the $\mathrm{Cr}$ concentration by about a factor of $c a$. $2 \mathrm{x}$. The nominal $\mathrm{Zr}$ concentration is slightly greater in the $650 \mathrm{~V}$ and C (350 and $340 \mathrm{ppm})$ than in the $650 \mathrm{E}(275$ ppm) coating bath. $650 \mathrm{~V}$ and $\mathrm{C}$ contain significant levels of $\mathrm{Zn}$ while the Fe level is greatest in $650 \mathrm{C}$ as compared to $650 \mathrm{E}$ and $\mathrm{V}$.

4.2 Surface morphology and chemical composition of the pretreated and conversion coated specimens 
Inclusions or constituent particles in AA7075 (Al-Zn-Mg-Cu) can be classified as Fe- and Si-containing. ${ }^{27-32}$ Common particles include binary $\mathrm{Al}_{2} \mathrm{Cu}$ and ternary $\mathrm{Al}_{2} \mathrm{CuMg}$ phases in addition to $\mathrm{Al}_{7} \mathrm{Cu}_{2} \mathrm{Fe}, \mathrm{Al}_{3} \mathrm{Fe}$ and $\mathrm{Mg}_{2} \mathrm{Si}^{27-32}$ Figure 3 shows secondary electron SEM micrographs and corresponding EDXS elemental line profiles for the alloy (A) as received, (B) after polishing, (C) after polishing + degreasing and (D) after polishing + degreasing + deoxidation. The AA7075-T6 specimen, as received (no sanding or polishing), displays deep ridges from the rolling process with intermetallic particles (IMPs) distributed across the surface. One is indicated by the IMP marking (Fig. 3A). The corresponding EDXS elemental line profile reveals the presence of three IMPs consisting of $\mathrm{Fe}$ with some $\mathrm{Cu}$ and $\mathrm{Cr}$. There is also background signal for $\mathrm{Mg}$ and $\mathrm{Zn}$ present consistent with their presence in the alloy (see Table 1). The image after polishing (Fig. 3B) reveals a considerably smoother surface with a slightly degraded IMP. The EDXS line profile reveals the Cu-Fe IMP in the center of the image. Not apparent in the image is the higher number density of small $\mathrm{Cu}$ particles decorating the surface, as compared to the as received panel. 

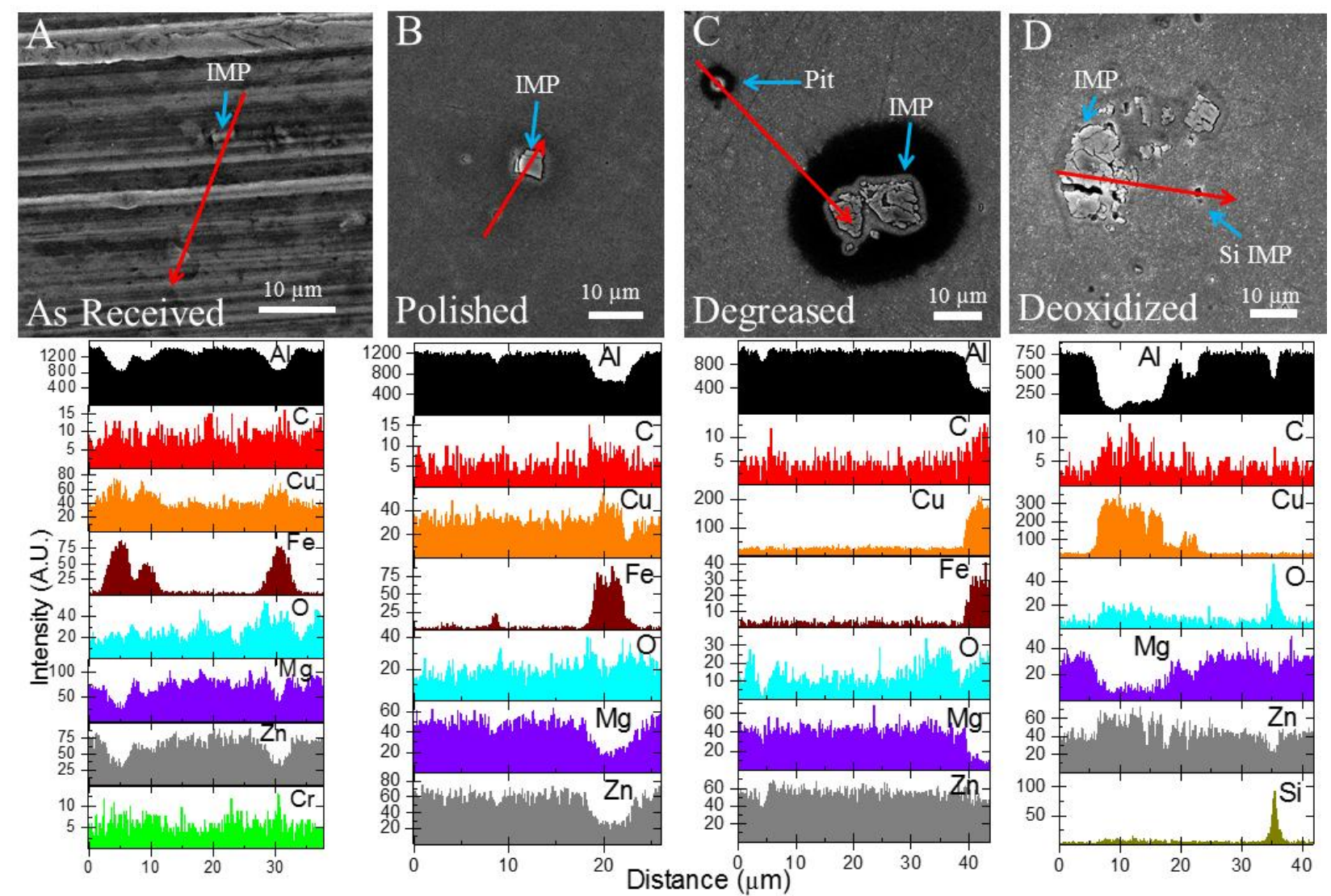

Figure 3. (top) Secondary electron SEM micrographs and (bottom) EDXS elemental line profiles recorded along the red arrows for the AA7075-T6 alloy (A) as received, (B) after polishing, (C) after polishing + degreasing, and (D) after polishing + degreasing + deoxidation. All images are at approximately the same magnification as indicated by the scale bars.

The SEM micrograph taken after polishing + degreasing (Fig. 3C) reveals a smooth surface with a damaged $\mathrm{Fe}-\mathrm{Cu}$ particle (center) displaying cracks and partially dissolved edges. The SEM micrograph taken after polishing + degreasing + deoxidation (Fig. 3D), shows a greater level surface roughening and pitting after the pretreatment. There are also cracks and evidence for dissolution within the $\mathrm{Cu}-\mathrm{Zn}$ particle seen in the center of the image. There is also the start of trenching around the IMPs in both images suggesting they are noble in potential relative to the $\mathrm{Al}$ matrix. ${ }^{28,31,33,34}$ During solution exposure, attack is mainly at the $\mathrm{Al}$ matrix phase and is ascribed to local galvanic attack of the more active matrix by the more noble 
particles. ${ }^{28,31,33,34}$ The dealloying within the intermetallic leaving behind a Cu-rich phase. EDXS data recorded across the center of the image reveals the large remaining phase is rich in $\mathrm{Cu}$ and $\mathrm{Zn}$. There is also a second smaller particle composed of Si and O, likely from the dissolution of $\mathrm{Mg}$ from a $\mathrm{Mg}_{2} \mathrm{Si}$ particle. The degreasing and deoxidation steps cause morphological and chemical changes on the alloy surface that are important to control for optimum conversion coating coverage. Ideally, one wants to minimize pitting and dissolution/redistribution of $\mathrm{Cu}$ particles over the surface during this pretreatment step. The EDXS data reveal the presence of C on all of the specimens particularly around the IMPs. This $\mathrm{C}$ likely exists as adsorbed carbonate species on the surface given that there is a general correlation between the $\mathrm{C}$ and $\mathrm{O}$ signal intensities.

Figure 4 shows (A) a secondary electron SEM micrograph of the conversion-coated alloy, (B) EDXS elemental line profiles recorded along the red arrow that crosses a coating precipitate particle and an IMP and (C) an EDXS spectrum recorded on the Al matrix at the green arrow away from any IMP. X-ray emission lines from the EDXS data (Fig. 4C) are presented for the uncoated or bare (grey shaded area) and the coated (red line) surface. The conversion coating was $650 \mathrm{E}$ and it was spray applied. 

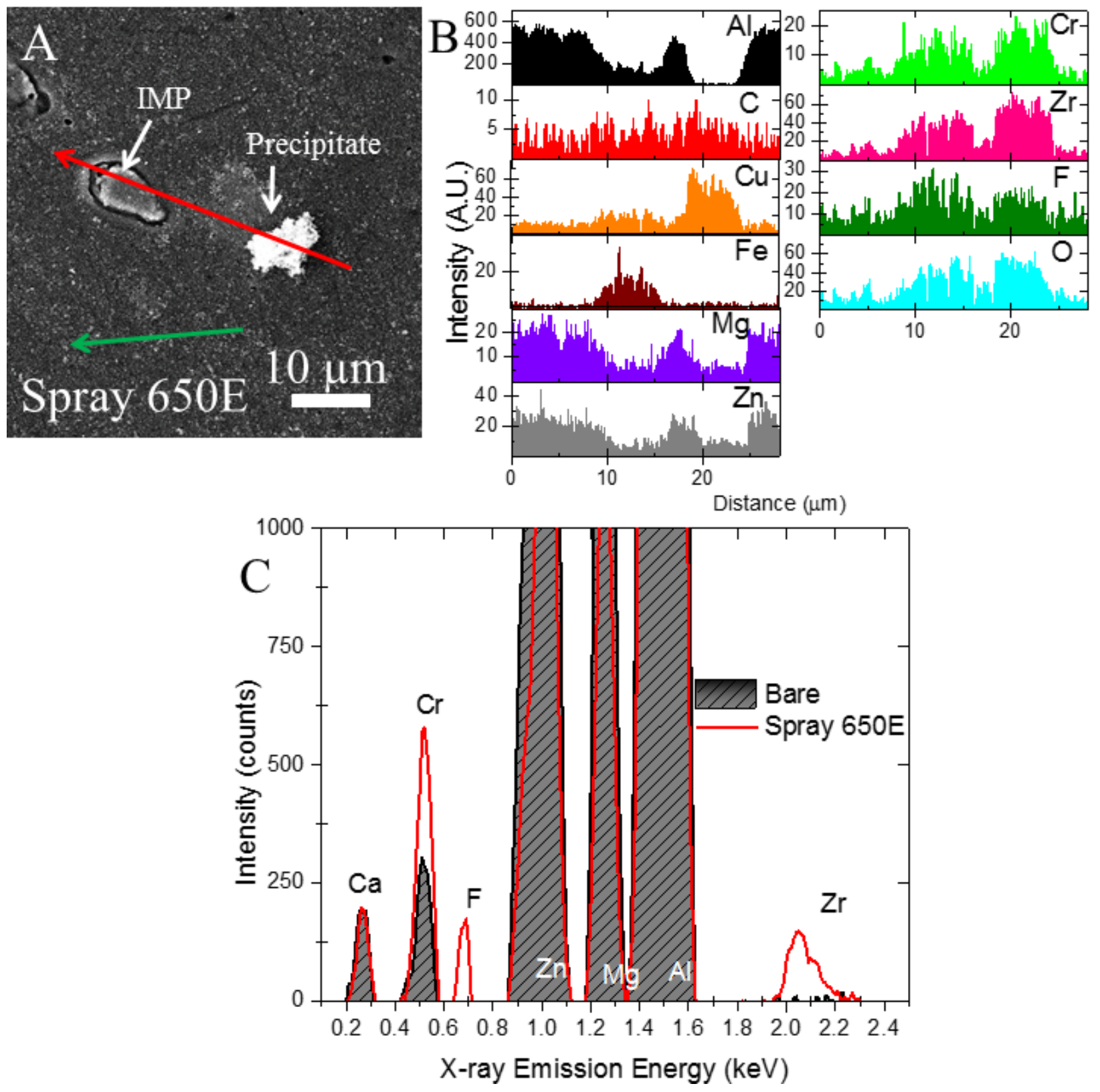

Figure 4. (A) Secondary electron SEM micrograph of the conversion-coated AA7075-T6 alloy. (B) EDXS elemental line profiles taken along the red arrow that crosses a coating precipitate and an intermetallic particle (IMP). (C) X-ray emission data for the uncoated (shaded grey) and conversion-coated (red line) alloy recorded at the green arrow away from any intermetallic particles. The conversion coating was $650 \mathrm{E}$ and it was spray applied.

The SEM micrograph reveals one large IMP near the center-left of the image and a smaller one near the white precipitate (center-right). The white precipitate particle is a constituent of the TCP coating. The surface consists of small (sub-micron), white precipitate 
particles decorating all regions of the surface. There is one large aggregate seen in the image that is 5-10 microns in diameter. Such large aggregates are not the norm however. The white coating precipitate particles also decorate the surface of the two IMPs seen in the center of the image. The EDXS elemental analysis data presented in Figure 4B reveal the larger IMP in the center-left of the image consists of $\mathrm{Cu}-\mathrm{Mg}-\mathrm{Zn}$ and the particle nearest the white precipitate is an $\mathrm{Fe}-\mathrm{Cu}$ phase. The EDXS elemental line profile data also reveal the presence of the coating elements, $\mathrm{Zr}$, $\mathrm{Cr}, \mathrm{O}$ and $\mathrm{F}$, in the large coating precipitate particle as well as on the surface of the two IMPs. There is clearly some coating enrichment (i.e., greater coating thickness) on and around the intermetallic phases. To verify that the Al matrix was also coated, EDXS spectra were recorded away from any intermetallic phase on the coated and uncoated or bare alloy. A comparison of the emission lines for the coating elements are presented in Figure 4C. The data reveal increased signal intensities for the coating elements, $\mathrm{Zr}, \mathrm{F}$ and $\mathrm{Cr}$, on the spray-coated panel. Consistent with past results, this sprayed-on conversion coating forms over all regions of the alloy with some enrichment on and around intermetallic phases. ${ }^{11,12,15-20,35}$

Figure 5 shows secondary electron SEM micrographs (top) and associated EDXS elemental data (bottom) for immersion-coated specimens of (A) $650 \mathrm{E}$, (B) $650 \mathrm{~V}$ and (C) $650 \mathrm{C}$. The formation of the coating is driven by a $\mathrm{pH}$ increase at the alloy interface due to the usual cathodic reactions of dissolved oxygen reduction and hydrogen evolution. ${ }^{12,16,19,20,35}$ 

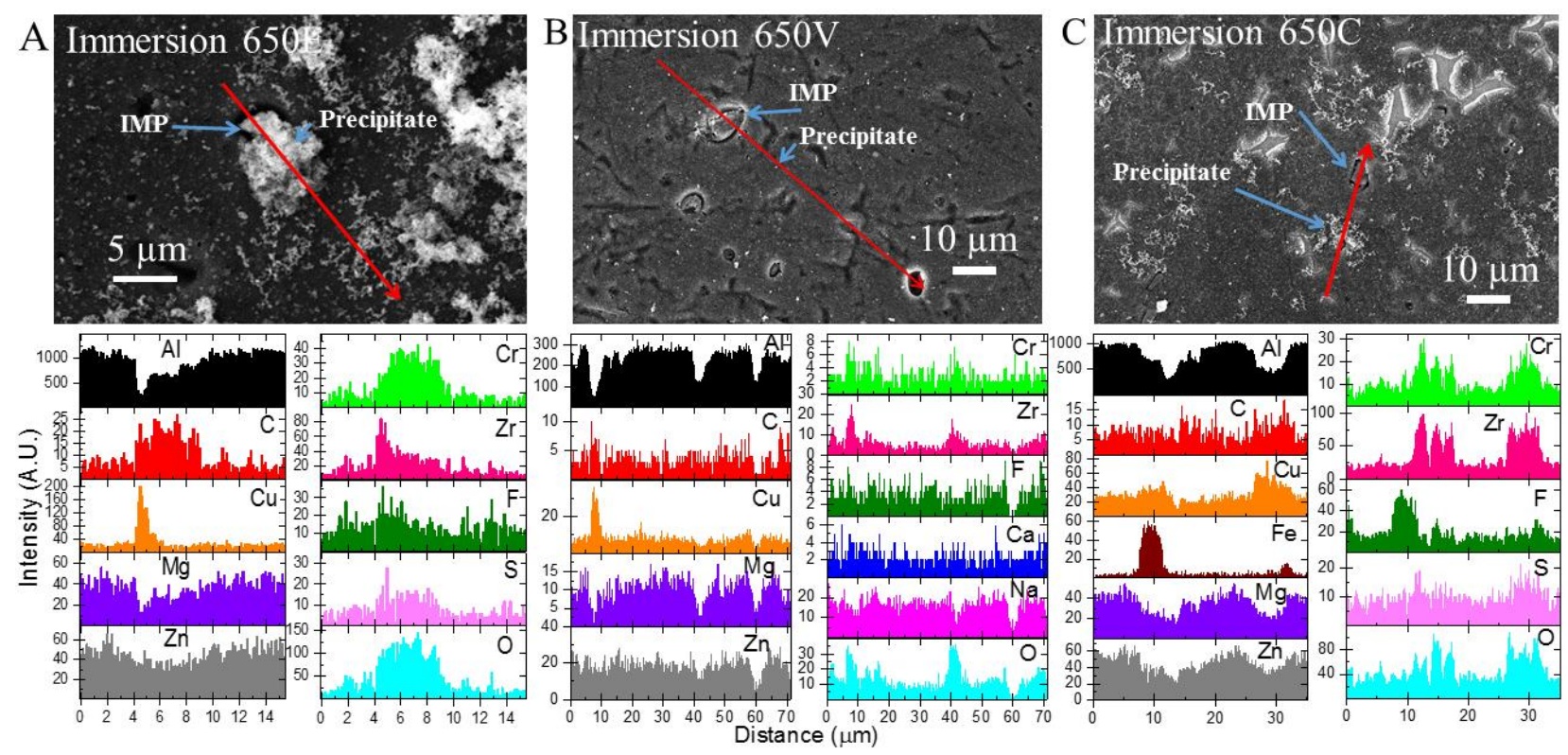

Figure 5. Secondary electron SEM micrographs and EDXS elemental line profile data for immersion-coated AA7075-T6 specimens of (A) $650 \mathrm{E}$, (B) $650 \mathrm{~V}$ and (C) $650 \mathrm{C}$. The EDXS data were taken along the directional red arrows shown in each image.

There are clear differences in the coating morphology/structure depending on the coating type.

The $650 \mathrm{E}$ coating (Fig. 5A) is characterized by small nodular precipitates that decorate the entire alloy surface. There is significant aggregation of coating particles on and around IMPs (i.e., coating enrichment). Based on the distribution of precipitate particles, the coating appears to form over all regions of the surface. The EDXS elemental line profiles, recorded along the red arrow, show the alloy signals for $\mathrm{Al}, \mathrm{Mg}$, and $\mathrm{Zn}$, which more or less track each other. This indicates these elements are dispersed within the aluminum matrix. The line profile also crosses a Cu-containing IMP. It is on and around this particle that the coating coverage, as evidenced by the accumulated white nodular features, is high. The coating enhancement around IMPs is likely due to the $\mathrm{pH}$ gradient that develops from the reduction of dissolved oxygen at these sites as compared to the surrounding $\mathrm{Al}$ matrix..$^{12,15,16,19,20,35}$ The characteristic coating elements are all co-localized: $\mathrm{Zr}, \mathrm{Cr}, \mathrm{O}$, and $\mathrm{F}$. There is also some $\mathrm{C}$ detected, likely from adsorbed carbonate species present on the IMPs. 
The $650 \mathrm{~V}$ coating (Fig. 5B) has a distinctly different morphology. There are some of the nodular precipitates decorating the surface, but these are fewer in number density than for the 650E coating. The alloy exhibits considerably more damage with numerous pits and what appears to be corrosion channels over the surface. Several IMPs are present in the region shown, each with a corrosion trench around the particle. This trenching occurs during the deoxidation step but also during the immersion coating. The cathodic activity of the $\mathrm{Cu}$-containing IMP for oxygen reduction causes localized oxidation of the nearby $\mathrm{Al}$ matrix leading to the trenching. ${ }^{28,29,31,32,34}$ The coating elements are co-localized: $\mathrm{Zr}, \mathrm{Cr}, \mathrm{F}$, and $\mathrm{O}$. The signal intensities for these elements are a factor of 10x less than the intensities on the 650E specimen, suggestive of a reduced nominal coating thickness. There are also trace amounts of $\mathrm{Ca}$ and $\mathrm{Na}$ co-localized with the coating elements. These elements are likely introduced during the final rinse with city tap water.

The $650 \mathrm{C}$ (Fig. 5C) coating appears thicker than the $650 \mathrm{~V}$ coating. Evidence for this is the cracking and detachment seen in the center and upper right of the micrograph. The characteristic white coating precipitates decorate the alloy surface. These are far greater in number density than on the $650 \mathrm{~V}$-coated specimen. The EDXS elemental line profile data reveal the metal alloy elements: $\mathrm{Al}, \mathrm{Mg}$, and $\mathrm{Zn}$. Closer analysis of the $\mathrm{Zn}$ profile also reveals that the signal intensity tracks the signals for $\mathrm{Zr}$ and $\mathrm{Cr}$ as this coating bath contains $\mathrm{Zn}$, unlike 650E. $650 \mathrm{~V}$ contains an equivalent level of $\mathrm{Zn}$ in the coating bath but, apparently due to the thinness of the coating, was not detected. The line profile crosses two $\mathrm{Fe}$ and $\mathrm{Cu}$-containing IMPs. Based on signal intensities, the particle on the lower end of the scan consists of more Fe than $\mathrm{Cu}$, while the opposite is true for the particle on the upper end. There is coating enrichment around the two IMPs: $\mathrm{Zr}, \mathrm{Cr}, \mathrm{Zn}, \mathrm{F}$, and $\mathrm{O}$. S is also co-localized in the coating as is some $\mathrm{C}$. 
The S likely originates from sulfate while the C likely comes from carbonate. This coating bath, unlike 650 E, contains relatively high levels of S and Zn (Fig. 2).

Raman imaging spectroscopy was performed on the immersion-coated specimens to probe for chromium species in the coating either as $\mathrm{Cr}(\mathrm{III})-\mathrm{O}\left(\mathrm{ca} .530 \mathrm{~cm}^{-1}\right)$ or $\mathrm{Cr}(\mathrm{VI})-\mathrm{O}(\mathrm{ca} .860$ $\mathrm{cm}^{-1}$ ). Raman spectroscopy has revealed the presence of both species in chromate conversion coatings formed on $\mathrm{Al}$ alloys, and on $\mathrm{Cr}(\mathrm{III})-\mathrm{O}$ and transiently formed $\mathrm{Cr}(\mathrm{VI})-\mathrm{O}$ species in $\mathrm{TCP}$ coatings on Al alloys. ${ }^{12,15,16,19,36}$ These peaks have been assigned based on the Raman spectra of reference compounds: $\mathrm{K}_{2} \mathrm{CrO}_{4}, \mathrm{Cr}_{2} \mathrm{O}_{3}, \mathrm{Cr}(\mathrm{OH})_{3}, \mathrm{CrF}_{3}, \mathrm{Cr}_{2}\left(\mathrm{SO}_{4}\right)_{3}$, and mixed $\mathrm{Cr}(\mathrm{III}) / \mathrm{Cr}(\mathrm{VI})$ oxides. $^{15,16,19.36}$ We previously reported on the transient formation of $\mathrm{Cr}(\mathrm{VI})-\mathrm{O}$ species in TCP coatings on AA2024-T3, 6061-T6 and 7075-T6 after overnight exposure to the laboratory air. $^{12,15,16,18}$ Others have published similar findings for the SurTec 650 E coating. ${ }^{19,36}$ The transient formation of $\mathrm{Cr}(\mathrm{VI})-\mathrm{O}$ species maybe linked to the formation of hydrogen peroxide generated by the reduction of dissolved oxygen at $\mathrm{Cu}$-rich intermetallic sites. ${ }^{12,15,16}$ The hydrogen peroxide then oxidizes local $\mathrm{Cr}(\mathrm{III})-\mathrm{O}$ species in the TCP coating to $\mathrm{Cr}(\mathrm{VI})-\mathrm{O}$ species according to the following two reactions:

$$
\begin{gathered}
\mathrm{O}_{2}+2 \mathrm{H}^{+}+2 \mathrm{e}^{-} \rightarrow \mathrm{H}_{2} \mathrm{O}_{2} \\
3 \mathrm{H}_{2} \mathrm{O}_{2}+2 \mathrm{Cr}^{+3} \rightarrow 2 \mathrm{Cr}^{+6}+6 \mathrm{OH}^{-}
\end{gathered}
$$

Figure 6 shows characteristic Raman spectra recorded along the indicated line profile for the three SurTec coatings on AA7075-T6. Spectra were recorded with $\sim 0.5 \mu \mathrm{m}$ spacing along the red arrow in the accompanying optical micrographs. The immersion-coated specimens were aged overnight in the laboratory atmosphere prior to the measurements. The spectra are different for each of the coatings but the mapping indicates the $\mathrm{Cr}(\mathrm{III})$ and $\mathrm{Cr}(\mathrm{VI})$ oxospecies are localized within the coating. Figure $6 \mathrm{~A}$ shows data for 650 E. The line profile crosses a white coating 
precipitate (see Fig. 5A) and at this particle peaks are seen at $543 \mathrm{~cm}^{-1}$ and $863 \mathrm{~cm}^{-1}$. These peaks are associated with the vibrational modes of $\mathrm{Cr}(\mathrm{III})-\mathrm{OH}$ from $\mathrm{Cr}(\mathrm{OH})_{3}$ and $\mathrm{Cr}(\mathrm{VI})-\mathrm{O}$ from $\mathrm{CrO}_{4}{ }^{2-15,16,20,36-40}$ It is possible that the peak at $543 \mathrm{~cm}^{-1}$ could also be associated with $\mathrm{Cr}(\mathrm{III})-\mathrm{F}$ modes of $\mathrm{CrF}_{3},{ }^{36}$ which may also be a constituent of the TCP coating due to $\mathrm{F}^{-}$sequestration in the interfacial region. ${ }^{11}$ It has been reported that solid $\mathrm{CrF}_{3}$ exhibits a strong Raman peak at 538 $\mathrm{cm}^{-1} .^{36}$ The aggregate particles that are characteristic of this and other TCP coatings consist of $\mathrm{ZrO}_{2} \bullet \mathrm{nH}_{2} \mathrm{O}, \mathrm{Cr}(\mathrm{OH})_{3} / \mathrm{CrF}_{3}$ and $\mathrm{CrO}_{4}{ }^{2-}$, and are present in the coating bath or form as occlusions during the coating precipitation process. ${ }^{12,13,15,16,19,20,36-40}$ For $650 \mathrm{~V}$ (Fig. 6B), there is weak scattering intensity centered at $568 \mathrm{~cm}^{-1}$ along most of the length of the line scan. The slight blue shift in this peak from $\sim 540 \mathrm{~cm}^{-1}$ could be due to the formation of $\mathrm{Cr}_{2} \mathrm{O}_{3}(\mathrm{Cr}(\mathrm{III})-\mathrm{O})$. In one location, there are also peaks at 790 and $969 \mathrm{~cm}^{-1}$. The $790 \mathrm{~cm}^{-1}$ peak is likely a downshifted mode reflective of $\mathrm{Cr}(\mathrm{VI})-\mathrm{O}$ while the $960 \mathrm{~cm}^{-1}$ peak may be reflective of S-O bond from sulfate in the coating. ${ }^{36}$ For $650 \mathrm{C}$ (Fig. 6C), the signal-to-noise ratio of the spectral features is considerably lower indicating fewer $\mathrm{Cr}$ species in the scattering volume. There is a peak at 539 $\mathrm{cm}^{-1}$ with a companion at $882 \mathrm{~cm}^{-1}$. This is likely due to the presence of a mixed $\mathrm{Cr}(\mathrm{III}) / \mathrm{Cr}(\mathrm{VI})$ oxide. ${ }^{38-40}$ The $547 \mathrm{~cm}^{-1}$ peak is present along most of the length probed and could be reflective of $\mathrm{Cr}(\mathrm{OH})_{3}$ or $\mathrm{CrF}_{3}$. 

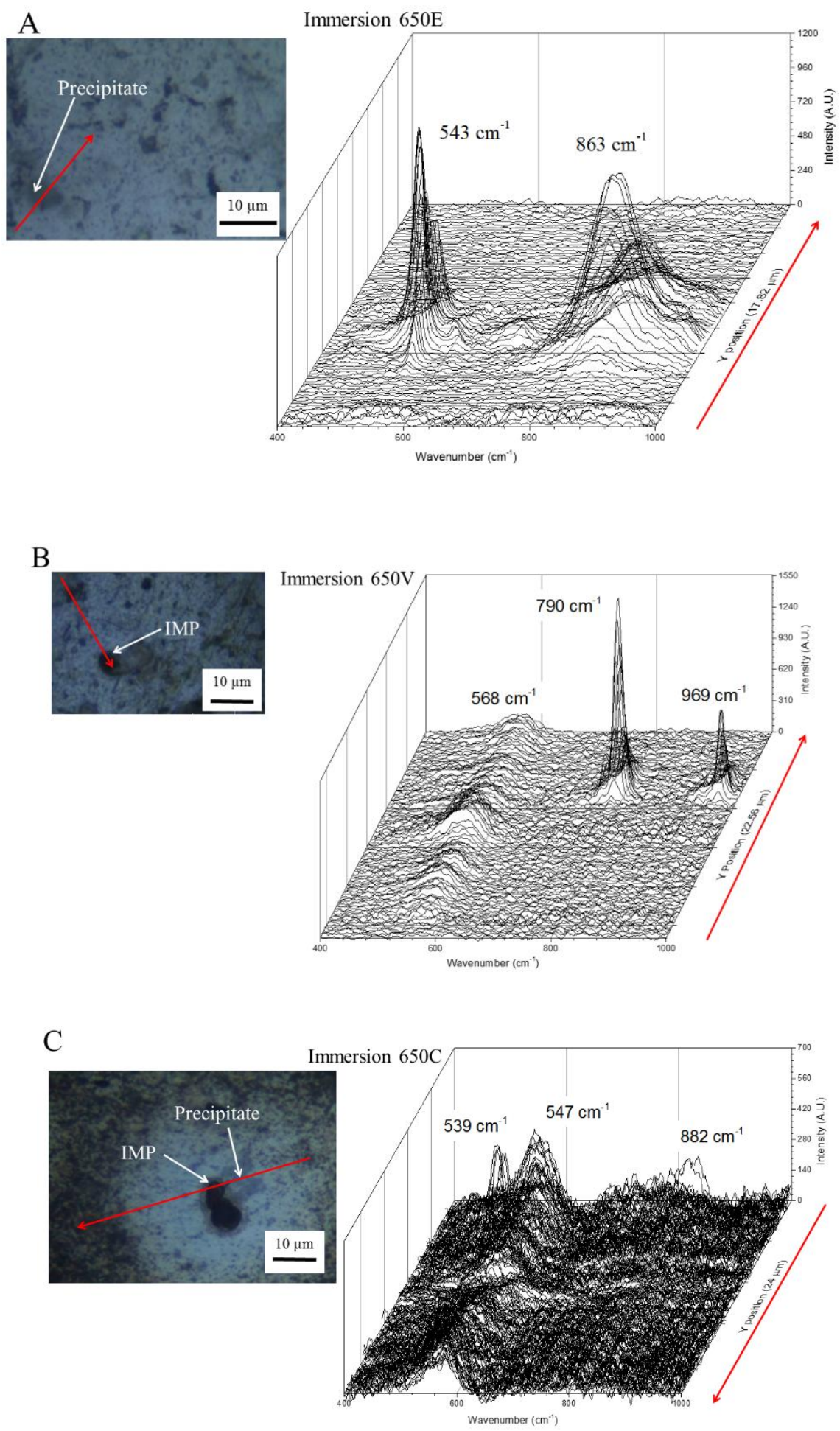

Figure 6. Raman spectroscopy line profile data for immersion-coated specimens (AA7075-T6) of (A) $650 \mathrm{E}$, (B) $650 \mathrm{~V}$ and (C) $650 \mathrm{C}$. The spectral data were recorded approximately every 0.5 
$\mu \mathrm{m}$ along the long red arrow directionally shown in each microscope image. The $y$-axis length in $\mathrm{A}$ is $17.3 \mu \mathrm{m}, \mathrm{B}$ is $22.6 \mu \mathrm{m}$ and $\mathrm{C}$ is $24 \mu \mathrm{m}$.

Figure 7 shows secondary electron SEM micrographs and associated EDXS elemental analysis data recorded along the red arrows for spray-coated specimens of (A) $650 \mathrm{E}$, (B) $650 \mathrm{~V}$, and (C) $650 \mathrm{C}$.
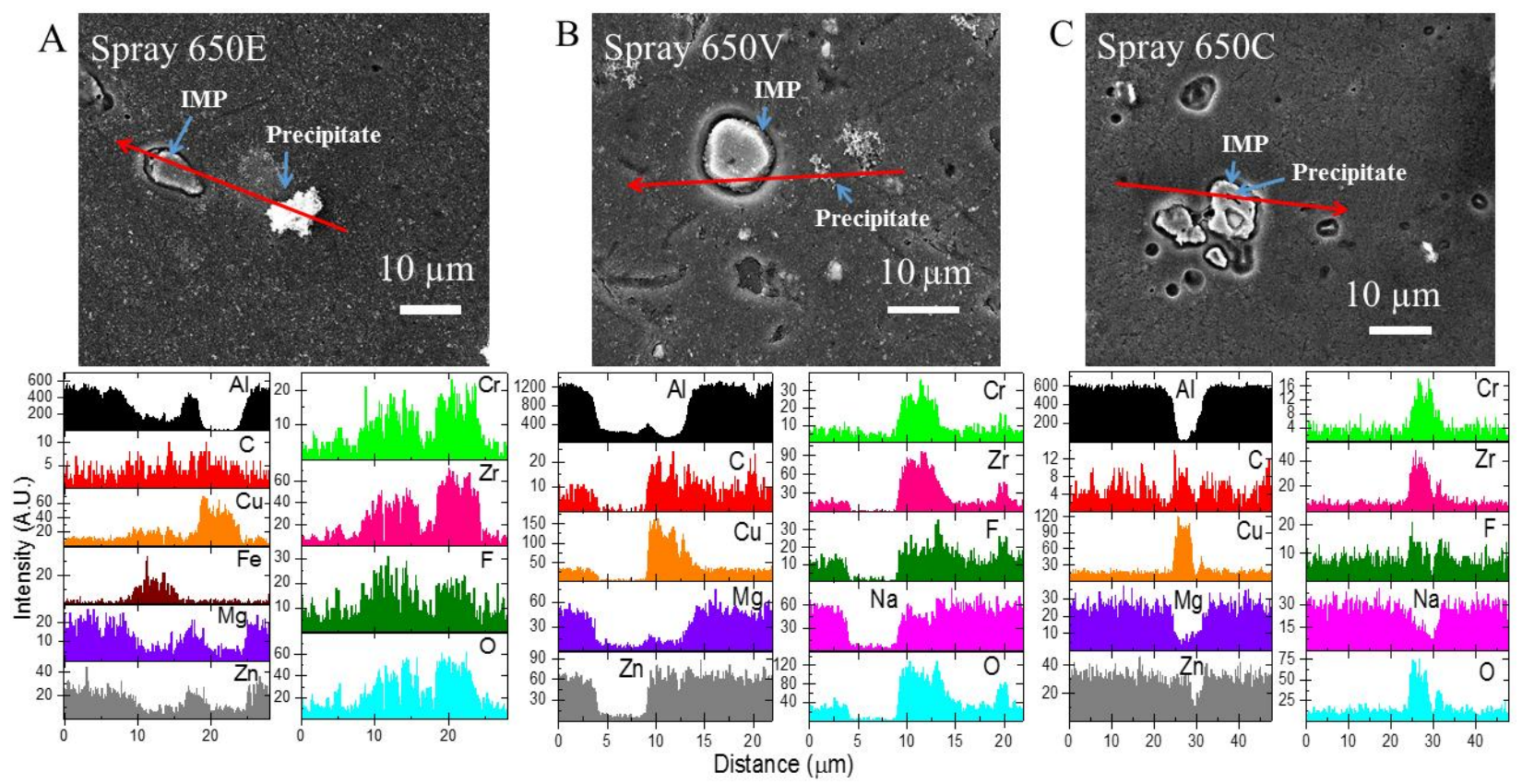

Figure 7. Secondary electron SEM micrographs and EDXS elemental line profile data for spraycoated AA7075-T6 specimens of (A) $650 \mathrm{E}$, (B) $650 \mathrm{~V}$ and (C) $650 \mathrm{C}$. The EDXS data were recorded directionally along the red line shown in each image.

The first observation is that there is much more pitting and trenching around intermetallic particles for all the sprayed coatings than for the immersion coatings. This is likely due to the thin solution layer for the spray application, which leads to a greater dissolved oxygen flux to the surface as compared to the immersion coating. The higher oxygen flux to the cathodic IMP sites drives the dissolution of the surrounding aluminum matrix. ${ }^{28,29,31,32,34,41,42}$ The second observation is the smoothness and homogeneity of the spray coatings as compared to the immersion coatings. The third observation is the relative absence of coating aggregates over the surface as compared to the immersion coatings. The far lower aggregate number for all the spray 
coated films could lead to better adhesion of primer layers. The coating morphology for $650 \mathrm{E}$ and $\mathrm{C}$ is distinctly different from their immersion counterparts. The $650 \mathrm{E}$ coating (Fig. 7A) is characterized by the nodular precipitates decorating the surface, but these are far lower in number density than for the immersion-coated specimen. There is one large coating aggregate (white precipitate) particle in the center of the image. Several intermetallic phases are visible, two in the center of the image, and they are not as covered by the coating as they tend to be for the immersion-coated $650 \mathrm{E}$, specifically the nodular precipitates. The EDXS line profile data reveal the alloy elements $(\mathrm{Al}, \mathrm{Mg}, \mathrm{Zn})$ and the coating elements $(\mathrm{Zr}, \mathrm{Cr}, \mathrm{O}, \mathrm{F})$ that are colocalized around the IMP and precipitate particle in the image. The particle labeled IMP is Ferich and the particle adjacent to the precipitate is $\mathrm{Cu}$-rich. The coating elements $(\mathrm{Zr}, \mathrm{Cr}, \mathrm{F}$ and $\mathrm{O})$ are all enriched around these sites. The $650 \mathrm{~V}$ spray-coated specimen (Fig. 7B) is characterized by a thin coating with a lower number of precipitate particles across the surface. The EDXS line profile indicates a co-localization of the coating elements $(\mathrm{Zr}, \mathrm{Cr}, \mathrm{O}, \mathrm{F})$ around the $\mathrm{Cu}-\mathrm{Zn} \mathrm{IMP}$ and a few visible precipitate particles in the center of the image. The $650 \mathrm{C}$ spray-coated specimen (Fig. 7C) shows little to no visible coating precipitates on the aluminum or IMPs. Despite the limited visual indication of a coating, the EDXS data revealed the coating elements $(\mathrm{Zr}, \mathrm{Cr}, \mathrm{O} \mathrm{F})$ to be co-localized on and around the intermetallic particles in the center of the image. Surprisingly, there is no $\mathrm{Zn}$ detected in the $650 \mathrm{C}$ and $\mathrm{V}$ coatings even though this element is present in the coating baths.

The spray-on coatings produce Raman spectral features in the $400-1000 \mathrm{~cm}^{-1}$ range that are different from was is seen for the immersion coatings. Figure 8A-C shows spectra for $650 \mathrm{E}$, V and C conversion coatings. For 650 E (Fig. 8A). Raman peaks are seen at 534, 788 and 963 $\mathrm{cm}^{-1}$ for an aggregate of coating particles covering an intermetallic particle. The $534 \mathrm{~cm}^{-1}$ peak 
is attributed to $\mathrm{Cr}(\mathrm{III})-\mathrm{O}$ as $\mathrm{Cr}(\mathrm{OH})_{3}$. The peak at $788 \mathrm{~cm}^{-1}$ is due to $\mathrm{Cr}(\mathrm{VI})-\mathrm{O}$ in an $\mathrm{Al}(\mathrm{III}) / \mathrm{Cr}(\mathrm{VI})$ 

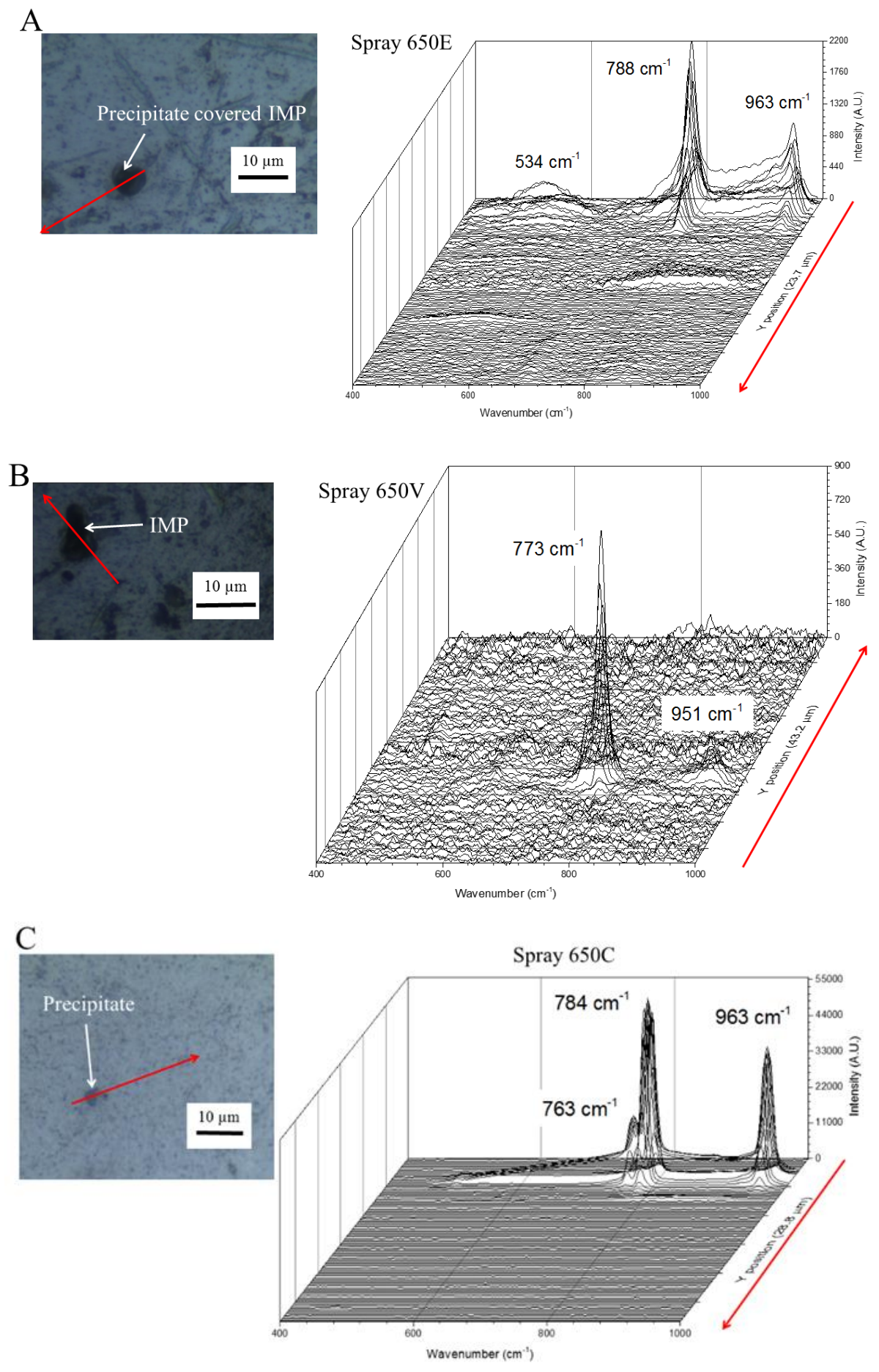

Figure 8. Raman spectroscopy line profile data for spray-coated specimens (AA7075-T6) of (A) $650 \mathrm{E}$, (B) $650 \mathrm{~V}$ and (C) $650 \mathrm{C}$. The spectral data were measured every $c a .0 .5 \mu \mathrm{m}$ along the red arrow directionally shown in each micrograph. 
mixed oxide. ${ }^{15,39,40}$ The $\mathrm{Cr}(\mathrm{VI})-\mathrm{O}$ peak position shifts toward lower energy with increasing $\mathrm{pH}^{15}$ The $963 \mathrm{~cm}^{-1}$ was not detected on the immersion coating and its origin is a bit unclear. Qi et al. have reported the presence of this peak in Raman spectra recorded for $650 \mathrm{E}$ and have attributed this peak to $\mathrm{S}-\mathrm{O}$ modes of sulphate possibly as $\mathrm{Fe}_{2}\left(\mathrm{SO}_{4}\right)_{3}$ or $\mathrm{Cr}_{2}\left(\mathrm{SO}_{4}\right)_{3}$ in the coating. The Raman spectra for $650 \mathrm{~V}$ and $\mathrm{C}$ showed no evidence for any $\mathrm{Cr}(\mathrm{III})-\mathrm{O}$ modes and only peaks at 770-790 $\mathrm{cm}^{-1}$ and $950-965 \mathrm{~cm}^{-1}$.

\subsection{TCP Coating Composition with Depth, Wettability and Thickness}

Auger electron spectroscopy (AES) depth profiling was performed on the immersion- and spray-coated 650 E specimens to investigate the coating chemical composition with depth. Representative data are presented in Figure 9A and B.
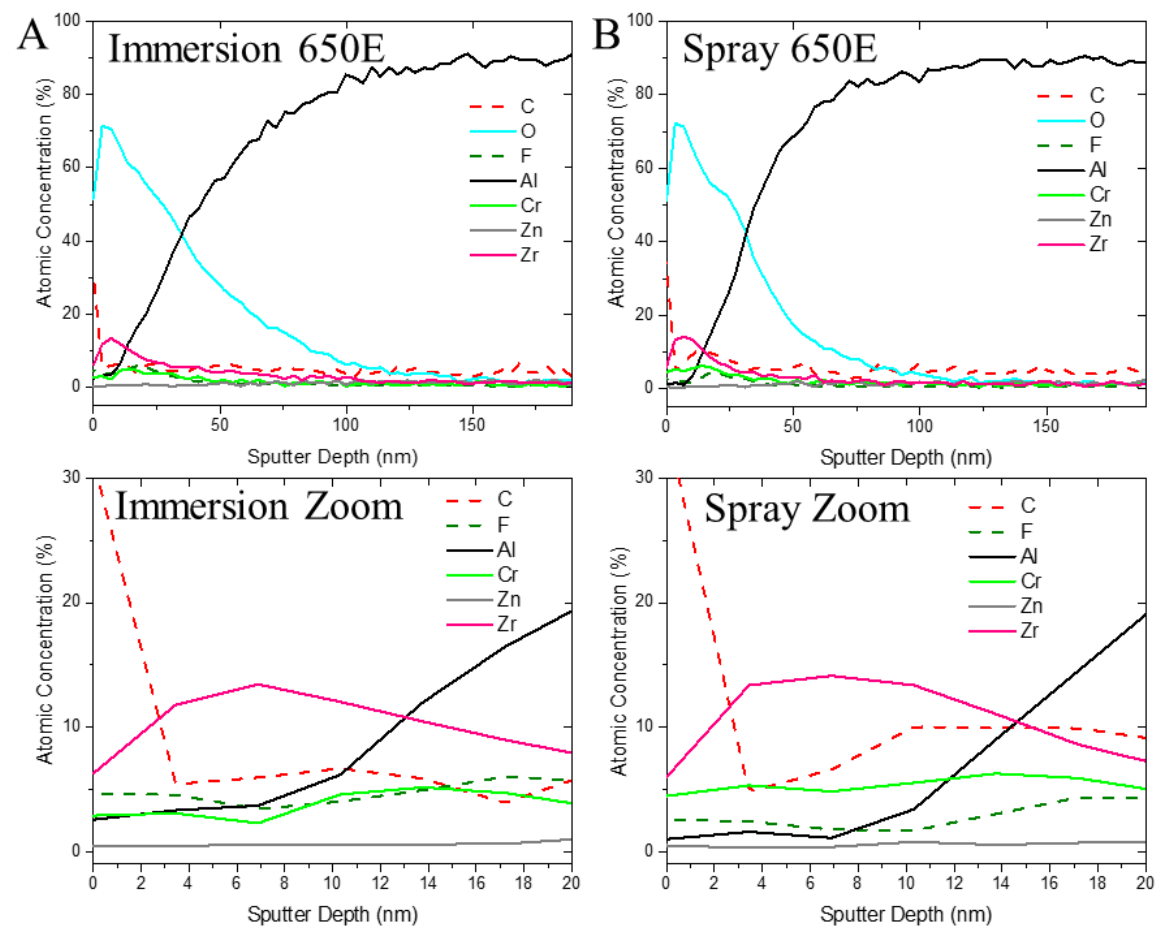

Figure 9. Auger electron spectroscopy depth profiles for AA7075-T3 specimens (A) immersioncoated and (B) spray-coated with $650 \mathrm{E}$. The top panels show full depth profiles while the bottom panels show expanded scale profiles over the top $20 \mathrm{~nm}$ of sputtering depth. The depth profiling was performed with $\mathrm{Ar}^{+}$at $10 \mathrm{keV}$. The sputter depth information is approximate as it is based on an $\mathrm{Ar}^{+}$sputter rate $6.2 \mathrm{~nm} / \mathrm{min}$ for $\mathrm{Ta}_{2} \mathrm{O}_{5}$. 
The measurement probes both the coating composition and the near-surface region of the Al alloy. We use the depth at which the Al signal reaches a constant value as the apparent coating thickness. Based on this, the immersion coating is $c a .100 \mathrm{~nm}$ thick while the spray coating is thinner at $c a .50 \mathrm{~nm}$. This is in qualitative agreement with the SEM images for the two coated specimens (vide supra) and ellipsometry data (vide infra). The $\mathrm{O}$ signal decays to near zero at these same depths. Profiles for the primary coating elements $(\mathrm{Zr}, \mathrm{Cr}, \mathrm{O}, \mathrm{F})$ are shown. It can be seen that the $\mathrm{Zr}$ reaches a maximum concentration of 15 at. \% in both coatings in the outer 30 $\mathrm{nm}$. The concentration decays with further depth into the coating. Cr reaches a maximum concentration of 5 at. $\%$ in both coatings in the center $30 \mathrm{~nm}$. There is an interfacial region in the 30-100 $\mathrm{nm}$ range where Al-O-F exists with some Zr. This interfacial region has been proposed previously. ${ }^{11,12,13,16,19,20,25,26}$ The F concentration increases slightly with depth for both coatings in the range from 3-6 at. \% consistent with some sequestration in the interfacial region. Signals for $\mathrm{S}$ or Fe were not recorded. Overall, the results indicate that the elemental composition with depth is similar for both application methods. The spray-coated film (3 min) is thinner than the immersion-coated film (4 min). Both have an interfacial region rich in $\mathrm{Al}, \mathrm{O}$ and $\mathrm{F}$.

Figure 10 presents static water contact angles measured on (A) uncoated and immersioncoated and (C) uncoated and spray-coated specimens. The data were recorded over a 7-day period of aging after coating formation. The aging was performed in the open laboratory atmosphere. 

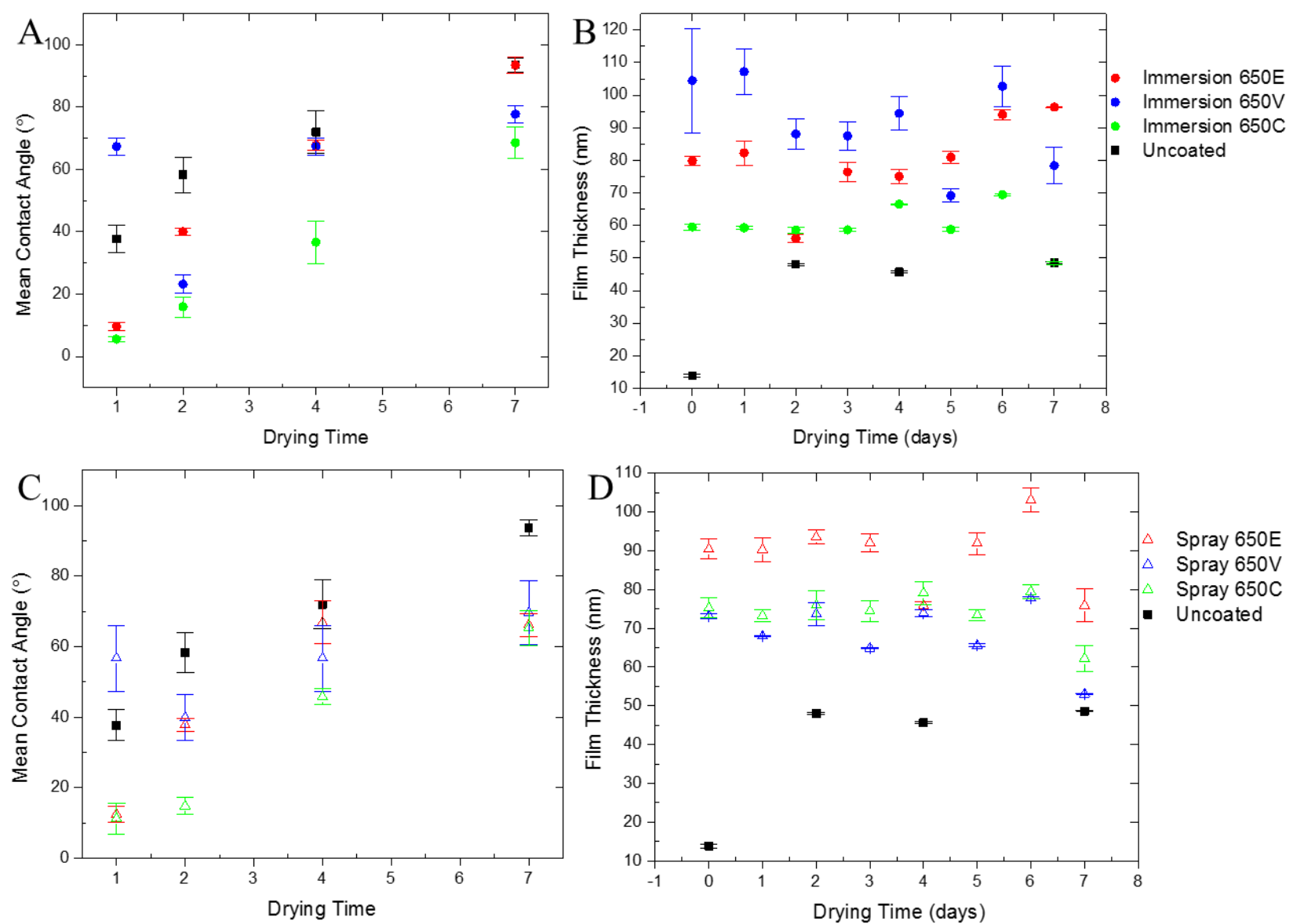

Figure 10. Static water contact angles on (A) immersion-coated and (C) spray-coated $650 \mathrm{E}$ (red), $650 \mathrm{~V}$ (green), $650 \mathrm{C}$ (blue), and uncoated (black) specimens. Film thickness, as determined from open air ellipsometry, for (B) immersion-coated and (D) spray-coated specimens. The results are presented over a 7-day period of aging in the open laboratory atmosphere. Data are presented as mean \pm standard error of the mean, $n \geq 3$.

Overall, the average of the leading and trailing edge contact angles $(n \geq 3)$ increased with aging time, consistent with the coating surface becoming progressively more hydrophobic. This is consistent with a changing surface chemistry over time. For both the immersion and spray coatings, $650 \mathrm{E}$ and $650 \mathrm{C}$ are quite hydrophilic $\left(\theta \sim 10^{\circ}\right)$ at day 1 , more so than $650 \mathrm{~V}(\theta \sim 60$ $80^{\circ}$ ). There may be more organic content (e.g., surfactants) or complexing agents in $650 \mathrm{~V}$, which would explain the more hydrophobic character. All the coatings become progressively more hydrophobic with aging time, as evidenced by the trend of increasing contact angle. This trend has been observed before for other TCP coatings on aluminum alloys. ${ }^{18}$ At day 7 , the most 
hydrophobic coating is $650 \mathrm{E}$ formed by immersion. The other two coating exhibit contact angles in the $60-80^{\circ}$ range. After 7 days, all three spray coatings have contact angles in the $60-80^{\circ}$ range. The contact angle for an uncoated specimen (degreased and deoxidized AA7075-T6) was measured over the same time period as a control. The uncoated alloy becomes progressively more hydrophobic with aging time due to the formation of a passivating oxide layer. Some of the hydrophobic character may result from the adsorption of hydrocarbon contaminants in the laboratory air as there is carbon on the coating surface as evidenced in the AES depth profiles and EDXS elemental analysis.

The coating thickness was measured by ellipsometry (open air) and the results are presented for (B) immersion-coated and (D) spray-coated specimens. Generally, the coating thicknesses are relatively constant over the 7-day aging period. $650 \mathrm{E}$ is the thickest of the coatings after the 7-day period when formed by both methods. At the 7-day point the mean thickness is $95 \mathrm{~nm}$ for the immersion coating and $75 \mathrm{~nm}$ for the spray-coating. The $95 \mathrm{~nm}$ is consistent with the thickness of this same SurTec coating ${ }^{25,26}$ on aluminum and Bonderite T5900 (Henkel) on AA2024-T3. ${ }^{18}$ This is in contrast to the densification and thinning of Bonderite T5900 over the same time period. ${ }^{18}$ The immersion-coated $650 \mathrm{E}, \mathrm{C}$ and $\mathrm{V}$ film thickness ranges from 80-100, 50-70 and 75-105 nm, respectively. At the 7-day point, the final mean thicknesses are 95,50 and $75 \mathrm{~nm}$ for $650 \mathrm{E}, \mathrm{C}$ and $\mathrm{V}$, respectively. For the spray coatings, the final mean thickness at the 7-day point was 75, 62 and $53 \mathrm{~nm}$, respectively, for $650 \mathrm{E}, \mathrm{C}$ and V. The spray coating thicknesses are somewhat constant over the drying period but decrease in thickness on day 7. Overall, the thicknesses of the spray-coated films $(3 \mathrm{~min})$ is less than the immersioncoated films (4 min). 


\section{Discussion}

The three most notable differences between the immersion and spray-on coatings are: (i) the much lower number of coating aggregate particles on the spray coatings, (ii) the smoother morphology for the spray coatings and (iii) the greater pitting and alloy surface damage for spray-coated specimens. Overall, the chemical composition and the elemental distribution of the primary coating elements is similar for all three TCP coatings applied by the two methods.

The major differences in the coating bath compositions, as determined from ICP-OES analysis, are (i) $\mathrm{Zr} / \mathrm{Cr}$ levels are greater in $650 \mathrm{~V}$ and $\mathrm{C}$, as compared to $650 \mathrm{E}$, (ii) $650 \mathrm{E}$ contains undetectable levels of $\mathrm{Zn}$ while $650 \mathrm{~V}$ and $\mathrm{C}$ contain 350-450 ppm, (iii) the level of S, likely as sulfate as part of a chromium sulfate salt, in $650 \mathrm{E}$ is 2-3x lower than the levels in 650 $\mathrm{V}$ and $\mathrm{C}$, and (iv) the concentration of $\mathrm{Fe}(\mathrm{sub} \mathrm{ppm}$ ) in $650 \mathrm{E}$ and $\mathrm{V}$ is $2 \mathrm{x}$ lower than the level in $650 \mathrm{C}$. The reason for the added $\mathrm{Fe}$ is unclear. There is no detectable $\mathrm{Ca}$ or $\mathrm{Mg}$ in any of the coating baths. The higher concentrations of $\mathrm{Zn}$ in $650 \mathrm{~V}$ and $\mathrm{C}$ are supposed to be primarily for coating coloration. Based on discussions with the supplier, $650 \mathrm{~V}$ and $\mathrm{C}$ contain additional complexing agents that aid in the coloration. We did not measure the organic content in the coating baths. The $650 \mathrm{E}$ has a chemical composition that most closely resembles the original NAVAIR TCP formulation.

The SEM and EDXS analysis reveal that all three conversion coatings form over all regions of the alloy surface with some coating thickening on and around intermetallic phases. The coating thickening is particularly true for $650 \mathrm{E}$ formed by immersion. This coating consists of colloidal aggregates that are composed of $\mathrm{Zr}$ and $\mathrm{Cr}$, based on EDXS analysis. Raman spectroscopy revealed that precipitates often contain a mixture of $\mathrm{Cr}(\mathrm{III})-\mathrm{O}\left(\mathrm{Cr}(\mathrm{OH})_{3}\right)$ and

transiently formed $\mathrm{Cr}(\mathrm{VI})-\mathrm{O}\left(\mathrm{CrO}_{4}{ }^{2-}\right)$ species. These aggregates may be occlusions that form 
during the coating precipitation process or pre-existing colloidal particles in the coating bath. It has been reported that $\mathrm{Zr}(\mathrm{OH})_{4}$ (hydrated zirconia) can form stable mono-disperse colloidal particles in the $\mathrm{pH} 3-4$ range. ${ }^{19,43}$ Recall the $\mathrm{pH}$ of the coating baths is 3.85 . The number density of these aggregates on the coated panels is greatest for $650 \mathrm{E}$ and $\mathrm{C}$. Very few are detected on the $650 \mathrm{~V}$-coated surface. The conversion coating is primarily hydrated zirconia with localized regions of $\mathrm{Cr}(\mathrm{OH})_{3}$ and transiently formed $\mathrm{Cr}^{+6}$ oxide. The also tends to be some sequestered fluoride within the coating, likely as part of a fluoroaluminate interfacial layer, such as $\mathrm{KAlF}_{4}{ }^{12,16}$ Based on the weaker EDXS signal intensities for the primary coating elements ( $\mathrm{Zr}$, $\mathrm{Cr}, \mathrm{O}$ and $\mathrm{F}$ ) for $650 \mathrm{~V}$, this coating is thinner than the other two. This may be due to slower precipitation kinetics in this coating bath. One reason for this could be that the interfacial $\mathrm{pH}$ increase during the coating formation process is not as alkaline for this coating as it is for the other two. ${ }^{35}$ The rate of hydrated zirconia precipitation strongly depends on the solution $\mathrm{pH}^{44}$ The coating formation kinetics were not investigated in this work. Cracking and delamination were observed for $650 \mathrm{C}$, something that has been reported before for $650 \mathrm{E} .{ }^{19}$ Cracking or peeling was not observed on any of the 650 E-coated panels used in this work.

The spray-coated $650 \mathrm{E}$ and $\mathrm{V}$ films are characterized by the presence of the aggregate particles decorating the alloy surface. There are very few aggregates in the $650 \mathrm{C}$ coating. The presence of these apparently loosely bound aggregates may negatively impact primer adhesion. This remains to be studied. Overall, the number density of these particles is far lower on the spray-coated than on the immersion-coated films for all three variants. The primary coating elements are detected over all regions of the panel; on and around intermetallic phases and the surrounding aluminum matrix. A significant difference in the alloy surface between the two 
methods is the greater level of pitting and trenching around intermetallic particles seen after spray-coating. This is attributed to the thinner solution layer that results in a higher flux of dissolved oxygen to the surface, particularly the cathodically-active intermetallic compounds. This should be considered when using spray application methods. Longer coating times may result in increased pitting and damage to the alloy surface and this could negatively impact the anti-corrosion properties of the conversion coating. The coating formation in both application methods is driven by a $\mathrm{pH}$ increase near the electrode surface due to activation of the aluminum (dissolution of the surface oxide layer) in the acidic fluoride bath and cathodic reactions that occur on the intermetallic compounds (dissolved oxygen reduction) and the activated aluminum (dissolved oxygen reduction and hydrogen evolution). The kinetics of dissolved oxygen reduction are expected to be more rapid at the $\mathrm{Cu}$-rich intermetallic phases and this is expected to produce a more alkaline $\mathrm{pH}$ gradient in these regions. This is likely the reason for the increased coating thickness on and around these particles.

The AES profiling data reveal similar chemical compositions for both the immersion and spray coatings (650 E) with depth. The conversion coating (650 E) formed by both methods has a biphasic chemical composition with an outer layer rich in $\mathrm{Zr}$ and $\mathrm{Cr}$ and an interfacial layer that contains $\mathrm{Al}, \mathrm{O}$ and $\mathrm{F}$ with some $\mathrm{Cr}$. This same biphasic structure has been reported previously for this $(650 \mathrm{E})^{19,20}$ and other TCP conversion coatings on aluminum alloys. ${ }^{12,16}$ The maximum $\mathrm{Zr} / \mathrm{Cr}$ atomic ratio in both coatings is $3: 1$. This ratio is slightly larger than the ratio in the coating bath, $\sim 2: 1$. This difference could be due to more rapid precipitation kinetics for hydrated zirconia $\left(\mathrm{ZrO}_{2} \bullet \mathrm{H}_{2} \mathrm{O}\right.$ or $\left.\mathrm{Zr}(\mathrm{OH})_{4}\right)$ as compared to $\mathrm{Cr}(\mathrm{OH})_{3}$. All three coatings were generally found to become more hydrophobic with aging time in air, presumably due to 
dehydration. This dehydration may produce a change in the molecular structure of the coating from $\mathrm{Zr}(\mathrm{OH})_{4}$ to $\mathrm{ZrO}_{2}$. Such a structural change would reduce the number of adsorbed water molecules and terminal $\mathrm{OH}$ functionalities to hydrogen bond with water. This trend of increasing hydrophobicity with aging time is consistent with what has been reported for other (Bonderite T5900) TCP coatings. ${ }^{18}$ The increased hydrophobicity may be an important issue to consider when priming these surfaces as changing surface wettability with time could affect aqueousbased primer adhesion.

Ellipsometry revealed the $650 \mathrm{E}$ coating formed by immersion is $c a .95 \mathrm{~nm}$ thick for a 4$\min (240 \mathrm{~s})$ immersion. This is in good agreement with the thicknesses reported by others for this conversion coating on aluminum ${ }^{25,26}$ and aluminum alloy. ${ }^{45}$ This is also consistent with the $c a$. $100 \mathrm{~nm}$ thickness reported for Bonderite T5900 TCP on aluminum alloy. ${ }^{18}$ The immersioncoated $650 \mathrm{E}, \mathrm{C}$ and V film thickness ranges from 80-100, 50-70 and 75-105 nm, respectively over a 7-day period of aging. At the 7-day point, the final mean thickness was 95, 50 and $75 \mathrm{~nm}$ for $650 \mathrm{E}, \mathrm{C}$ and $\mathrm{V}$, respectively. For the spray coatings, the final mean thickness at the 7-day point was 75,62 and $53 \mathrm{~nm}$, respectively, for $650 \mathrm{E}, \mathrm{C}$ and V. The spray coating thicknesses are relatively constant over the drying period with a decrease seen on day 7. Overall, the thicknesses of the spray-coated films ( $3 \mathrm{~min}$ ) is less than the immersion-coated films (4 min). No inferences can be made about the defect density or the micro-/nanoporosity of the different coatings from the data in hand. It is known that the molecular structure of precipitated zirconia depends on the solution $\mathrm{pH} \cdot{ }^{44}$

Finally, Raman spectroscopy provides evidence for the presence of localized $\mathrm{Cr}(\mathrm{III})-\mathrm{O}$ and transiently formed $\mathrm{Cr}(\mathrm{VI})-\mathrm{O}$ species in the coatings. For the three different $\mathrm{TCP}$ variants formed by immersion, the data clearly reveal the presence of localized $\operatorname{Cr}(\mathrm{III})$ and $\mathrm{Cr}(\mathrm{VI})$ 
species. For $650 \mathrm{E}$, there isolated regions in the coating where peaks at 543 and $863 \mathrm{~cm}^{-1}$ are colocalized. This is the case for the nodular precipitate particles that decorate the surface. For 650 $\mathrm{V}$, there are larger regions in the coating where scattering at $568 \mathrm{~cm}^{-1}$ is detected along with peaks at 568, 790 and $969 \mathrm{~cm}^{-1}$. Examples can be found where the co-localization of these bands is seen on and around intermetallic particles. For $650 \mathrm{C}$, the signal-to-noise ratio of the spectra is lower than that for $650 \mathrm{E}$ and $\mathrm{V}$ due to its thinner nature. The coating is characterized by extended regions of scattering at $547 \mathrm{~cm}^{-1}$ on both the aluminum matrix and around intermetallic particles.

The results indicate that the coatings contain $\mathrm{Cr}(\mathrm{III})-\mathrm{O}$ species as well as isolated regions of transiently formed $\mathrm{Cr}(\mathrm{VI})-\mathrm{O}$ species. Although the equilibrium distribution of different $\mathrm{Cr}(\mathrm{VI})-\mathrm{O}$ species, $\mathrm{CrO}_{4}{ }^{2-}, \mathrm{HCrO}_{4}{ }^{-}$and $\mathrm{Cr}_{2} \mathrm{O}_{7}{ }^{2-}$, is complex and depends on the local $\mathrm{pH}$, the $\mathrm{Cr}(\mathrm{VI})-\mathrm{O}$ bands are positioned in the $840-904 \mathrm{~cm}^{-1}$ range, which easily distinguishes them from the $\mathrm{Cr}(\mathrm{III})-\mathrm{O}$ bands in the range of $520-580 \mathrm{~cm}^{-1}$. 12,15,45,46 Reference spectra for $\mathrm{Cr}_{2} \mathrm{O}_{3}$ and $\mathrm{Cr}(\mathrm{OH})_{3}$ exhibit peaks at 536 and $526 \mathrm{~cm}^{-1}$, respectively. These two $\mathrm{Cr}(\mathrm{III})$ species have indistinguishable spectral features. The difference in band shape and peak position is due to differential states of hydration (i.e., bond length). ${ }^{15,37,38,47,48} \mathrm{CrF}_{3}$ exhibits scattering near 547 $\mathrm{cm}^{-1}$ so the low frequency mode could reflect the presence of $\mathrm{Cr}(\mathrm{OH})_{3}$ as well as $\mathrm{CrF}_{3} .{ }^{36} \mathrm{In}$ summary, the $\mathrm{Cr}(\mathrm{III})$ species is $\mathrm{Cr}(\mathrm{OH})_{3}$ and the transiently formed $\mathrm{Cr}(\mathrm{VI})$ species is likely $\mathrm{CrO}_{4}{ }^{2-}$ or $\mathrm{HCrO}_{4}^{-}$.

The Raman spectral features are a little different for the spray-on coatings. Spectra obtained from the aggregate particles in $650 \mathrm{E}$, which are normally concentrated on and around 
intermetallic phases, exhibited bands at 534,788 and $963 \mathrm{~cm}^{-1}$. The $534 \mathrm{~cm}^{-1}$ peak is attributed to $\mathrm{Cr}(\mathrm{III})-\mathrm{O}$ and the $788 \mathrm{~cm}^{-1}$ peak is ascribed to $\mathrm{Cr}(\mathrm{VI})-\mathrm{O}$ as part of a mixed $\mathrm{Al}(\mathrm{III}) / \mathrm{Cr}(\mathrm{VI})$ mixed oxide. $^{49}$ The $\mathrm{Cr}(\mathrm{VI})-\mathrm{O}$ mode in this mixed oxide shifts to lower energy with increasing solution $\mathrm{pH}^{15}$ The origin of the band at $963 \mathrm{~cm}^{-1}$ has not been conclusively established yet. It is present in all of the TCP coating variants formed by spray. Qi et al. have reported the presence of this peak in Raman spectra recorded for $650 \mathrm{E}$ and have attributed it to S-O modes of sulphate possibly as $\mathrm{Fe}_{2}\left(\mathrm{SO}_{4}\right)_{3}$ or $\mathrm{Cr}_{2}\left(\mathrm{SO}_{4}\right)_{3}$ in the coating. ${ }^{36}$ The Raman spectra for $650 \mathrm{~V}$ and $\mathrm{C}$ showed no evidence for any $\mathrm{Cr}(\mathrm{III})-\mathrm{O}$ modes and only peaks at $770-790 \mathrm{~cm}^{-1}$ and $950-965 \mathrm{~cm}^{-1}$.

\section{Conclusions}

Three different TCP coating variants (SurTec $650 \mathrm{E}, \mathrm{V}$ and C) formed by immersion and spray on AA7075-T6 were characterized for morphology, coating chemistry, film thickness, and hydrophobicity. The following are the key findings:

1. The $\mathrm{Cr}$ concentration is similar for all three coating baths at $\sim 150 \mathrm{ppm}$. The nominal $\mathrm{Zr}$ concentration in all three baths is higher than the Cr concentration by about a factor of $c a$. $2 \mathrm{x}$. The nominal $\mathrm{Zr}$ concentration is slightly greater in $650 \mathrm{~V}$ and $\mathrm{C}$ (350 and $340 \mathrm{ppm}$ ) than in 650 $\mathrm{E}(275 \mathrm{ppm}) .650 \mathrm{~V}$ and $\mathrm{C}$ contain significant levels of $\mathrm{Zn}$ while the Fe level is greatest in $650 \mathrm{C}$ as compared to $650 \mathrm{E}$ and $\mathrm{V}$.

2. The conversion coatings (immersion or spray) form over all regions of the alloy surface with some thickening on and around intermetallic particles. Based on EDXS elemental signal intensities, greater coating thickness is observed for $650 \mathrm{E}$ and $\mathrm{C}$. The $650 \mathrm{C}$ coating is characterized by cracks and delamination while the other two are devoid of these defects. 
3. Conversion coatings formed by spray are characterized fewer coating aggregate particles that their immersion-coated counterparts. A significant difference is the increased alloy pitting and trenching around intermetallic particles when the coatings are spray applied. Care should be taken regarding the duration of the formation process when applying these conversion coatings by spray.

4. AES depth profiling indicates the 650 E conversion coating (immersion and spray) consists of a biphasic structure. An outer layer $(30-50 \mathrm{~nm})$ exists that is rich in $\mathrm{Zr}$ and $\mathrm{Cr}$. There is also an interfacial region $(\sim 50 \mathrm{~nm})$ rich in $\mathrm{Al}, \mathrm{O}, \mathrm{F}$ and some $\mathrm{Cr}$. The maximum $\mathrm{Zr} / \mathrm{Cr}$ atomic concentration ratio is $c a .3: 1$ in the coatings.

5. The conversion coatings (immersion or spray) become more hydrophobic over a 7-day aging period in the laboratory air. For both the immersion and spray-on coatings, $650 \mathrm{E}$ and 650 $\mathrm{C}$ are quite hydrophilic $\left(\theta \sim 10^{\circ}\right)$ at day 1 , more so that $650 \mathrm{~V}\left(\theta \sim 60-80^{\circ}\right)$. Static water contact angles at day 7 are $60-90^{\circ}$ for all the coatings.

6. Ellipsometry data indicate $650 \mathrm{E}$ is the thickest of the three coatings. At the 7-day point, the final mean thicknesses of the immersion coatings are 95,50 and $75 \mathrm{~nm}$ for $650 \mathrm{E}, \mathrm{C}$ and $\mathrm{V}$, respectively. For the spray coatings, the final mean thickness at the 7-day point was 75, 62 and $53 \mathrm{~nm}$, respectively, for $650 \mathrm{E}, \mathrm{C}$ and $\mathrm{V}$.

7. Raman spectroscopic imaging reveals the presence of localized regions of $\mathrm{Cr}(\mathrm{III})-\mathrm{O}$ species (e.g., $\left.\mathrm{Cr}(\mathrm{OH})_{3}\right)$ with some of these regions also containing transiently-formed $\mathrm{Cr}(\mathrm{VI})-\mathrm{O}$ species (e.g., $\mathrm{CrO}_{4}{ }^{2-}, \mathrm{HCrO}_{4}{ }^{-}$). $\mathrm{The} \mathrm{Cr}(\mathrm{III}) / \mathrm{Cr}(\mathrm{VI})$ species are often present in the coating aggregate particles that decorate the surface and the intermetallic particles. These particles are potential reservoirs of $\mathrm{Cr}(\mathrm{VI})$. 


\section{Acknowledgements}

The research was made possible by a grant from the Office of Naval Research (SeaBased Aviation Program), N00014-15-1-2005 (William Nickerson, Program Officer). The authors also thank Dr. Nabil Zaki (Technical Advisor, SurTec, Inc.) for providing the degreaser, deoxidizer and TCP coating solutions, and for providing technical assistance. The authors also thank Craig Matzdorf (NAVAIR) for his technical expertise on the coatings. 


\section{$\underline{\text { References }}$}

1. J. LaScala, Non-chromate/No-VOC coating systems for DoD applications, (WP-1521), Final Report, SERDP, 2009.

2. M. Costa, Toxicity and Carcinogenicity of $\mathrm{Cr}(\mathrm{VI})$ in Animal Models and Humans, Critical Rev. Toxicol. 27 (1997) 431-442.

3. S. Mishra and R. N. Bharagava, Toxic and genotoxic effects of hexavalent chromium in environment and its bioremediation strategies. J. Environ. Sci. Health C. Environ. Carcinog. Ecotoxicol. Rev. 34 (2016) 1-32.

4. R. L. Twite and G. P. Bierwagen. Review of alternatives to chromate for corrosion protection of aluminum aerospace alloys, Prog. Org. Coat. 33 (1998) 91-100.

5. M. W. Kendig and R. G. Buchheit. Corrosion inhibition of aluminum and aluminum alloys by soluble chromates, chromate coatings, and chromate-free coatings, Corrosion 59 (2003) $379-400$.

6. H. Guan and R. G. Buchheit. Corrosion protection of aluminum alloy 2024-T3 by vanadate conversion coatings, Corrosion 60 (2004) 284-296.

7. C. A. Matzdorf, W. C. Nickerson, Jr., E. N. Beck, A. S. Schwartz and J. L. Green, U.S. Patent Application Publication, Non-Chromium Coatings for Aluminum, US2007/0095436 A1, May 3, 2007.

8. L. Li, B. W. Whitman, C. A. Munson, R. Estrada, C. A. Matzdorf and G. M. Swain. Structure and corrosion performance of a non-chromium process (NCP) $\mathrm{Zr} / \mathrm{Zn}$ pretreatment conversion coating on aluminum alloys, J. Electrochem. Soc. 163 (2016) C1-11.

9. S. L. Suib, J. LaScala, W. Nickerson, A. Fowler and N. Zaki, Determination of hexavalent chromium in NAVAIR trivalent chromium process (TCP) coatings and process solutions, Metal Finishing 107 (2009) 28, 31-34.

10. A. Iyer, W. Willis, S. Frueh, W. Nickerson, A. Fowler, J. Bames, L. Hagos, J. Escarsega, J. La Scala and S.L. Suib, Characterization of NAVAIR trivalent chromium process (TCP) coatings and solutions, Plating and Surface Finishing 5 (2010) 32-42.

11. X. C. Dong, P. Wang, S. Argekar and D. W. Schaefer, Langmuir 26 (2010) 10833-10841. 
12. L.L. Li, G. P. Swain, A. Howell, D. Woodbury and G. M. Swain, The formation, structure, electrochemical properties and stability of trivalent chromium process (TCP) coatings on AA2024, J. Electrochem. Soc. 158 (2011) C274-283.

13. Y. Guo and G. S. Frankel. Characterization of trivalent chromium process coating on AA2024-T3, Surf. Coat. Technol. 206 (2012) 3895-3902.

14. Y. Guo and G. S. Frankel. Active corrosion inhibition of AA2024-T3 by trivalent chrome process treatment, Corrosion 68 (2012) 045002-1-045002-10.

15. L. L. Li, D. Y. Kim and G. M. Swain. Transient formation of chromate in trivalent chromium process (TCP) coatings on AA2024, J. Electrochem. Soc. 159 (2012) C326C333.

16. L. L. Li and G. M. Swain, Formation and structure of trivalent chromium process coatings on aluminum alloys 6061 and 7075, Corrosion 69 (2013) 1205-1219.

17. L. L. Li, K. P. Doran and G. M. Swain, Electrochemical characterization of trivalent chromium process (TCP) coatings on AA6061 and 7075. J. Electrochem. Soc . 160 (2013) C396-C401.

18. L. L. Li and G. M. Swain, Effects of aging temperature and time on the corrosion protection provided by trivalent chromium process coatings on AA2024-T3. ACS Appl. Mater. Interfaces 5 (2013) 7923-7930.

19. J. T. Qi, T. Hashimoto, J. R. Walton, X. Zhou, P. Skeldon and G. E. Thompson, Trivalent chromium conversion coating formation on aluminum, Surf. Coat. Technol. 280 (2015) 317-329.

20. J. Qi, T. Hashimoto, J. Walton, X. Zhou, P. Skeldon and G. E. Thompson, Formation of a trivalent chromium conversion coating on AA2024-T351 alloy, J. Electrochem. Soc. 163 (2016), C25-C35.

21. J. Qi, T. Hashimoto, G. E. Thompson and J. Carr, , Influence of water immersion posttreatment parameters on trivalent chromium conversion coatings formed on AA2024T351 alloy, J. Electrochem. Soc. 163 (2016) C131 -138.

22. Z. Feng, G. S. Frankel and C. A. Matzdorf, Quantification of accelerated corrosion testing of coated AA7075-T6, J. Electrochem. Soc. 161 (2014) C42-C49.

23. Z. Feng, J. Boerstler, G. S. Frankel and C. A. Matzdorf, Effect of surface pretreatment on galvanic attack of coated Al alloy panels. Corrosion 71 (2015) 771-783. 
24. J. R. Davis, International, A. S. M.; Handbook, C., Aluminum and aluminum alloys. ASM International: Materials Park, Ohio, 1994.

25. S. Dardona and M. Jaworowski, In situ spectroscopic ellipsometry studies of trivalent chromium coating on aluminum. Appl. Phys. Lett. 97 (2010) 181908-1 - 181908-3.

26. S. Dardona, L. Chen, M. Kryzman and M. Jaworowski, Polarization controlled kinetics and composition of trivalent chromium process coatings on aluminum, Anal. Chem. 83 (2011) 6127-6131.

27. M. Gao, C. R.Feng and R. P. Wei, An analytical electron microscopy study of constituent particles in commercial 7075-T6 and 2024-T3 alloys. Metall. Mater. Trans. A 29 (1998) 1145-1151.

28. N. Birbilis and R. G. Buchheit, Electrochemical characteristics of intermetallic phases in aluminum alloys - An experimental survey and discussion. J. Electrochem. Soc. 152 (2005) B140-B151.

29. N. Birbilis, M. K.. Cavanaugh and R. G. Buchheit, Electrochemical behavior and localized corrosion of $\mathrm{Al}_{7} \mathrm{Cu}_{2} \mathrm{Fe}$ particles in aluminum alloy 7075-T651, Corros. Sci. 48 (2006) 4202-4215.

30. S. Dey, M. K. Gunjan and I. Chattoraj, Effect of temper on the distribution of pits in AA7075 alloys, Corros. Sci. 50 (2008) 2895-2901.

31. R. G. Buchheit and N. Birbilis, Electrochemical microscopy: An approach for understanding localized corrosion in microstructurally complex metallic alloys, Electrochim. Acta 55 (2010) 7853-7859.

32. S. S. Singh, E. Y. Guo, H. X. Xie and N. Chawla, Mechanical properties of intermetallic inclusions in AA7075 alloys by micropillar compression, Intermetallics 62 (2015) 69-75.

33. G. S. Frankel, 2015 W.R. Whitney Award Lecture: The Effects of Microstructure and Composition on Al Alloy Corrosion, Corrosion 71 (2015) 1308-1320.

34. N. Birbilis and R. G. Buchheit, Investigation and discussion of characteristics for intermetallic phases common to aluminum alloys as a function of solution $\mathrm{pH}, \mathbf{J}$. Electrochem. Soc. 155 (2008) C117-C126.

35. L. Li, A. L. Desouza and G. M. Swain, In situ pH measurement during the formation of conversion coatings on aluminum alloy (AA2024), Analyst 138 (2013) 4398-4402. 
36. J. Qi, J. Walton, G. E. Thompson, S. P. Albu and J. Carr, Spectroscopic studies of chromium VI formed in the trivalent chromium conversion coatings on aluminum. J. Electrochem. Soc. 163 (2016) C357-C363.

37. B. M. Weckhuysen and I. E. Wachs, In situ raman spectroscopy of supported chromium oxide catalysts: reactivity studies with methanol and butane. J. Phys. Chem. 100 (1996) 14437-14442.

38. B. L. Hurley and R. L. McCreery, Raman spectroscopy of monolayers formed from chromate corrosion inhibitor on copper surfaces. J. Electrochem. Soc. 150 (2003) B367B373.

39. L. Xia and R. L. McCreery, Chemistry of a chromate conversion coating on aluminum alloy AA2024- T3 probed by vibrational spectroscopy. J. Electrochem. Soc. 145 (1998) 3083-3089.

40. J. D. Ramsey and R. L. McCreery, Raman microscopy of chromate interactions with corroding aluminum alloy 2024-T3. Corros. Sci. 46 (2004) 1729-1739.

41. Z. Feng, J. Boerstler, G. S. Frankel and C.A. Matzdorf, Effect of surface pretreatment on galvanic attack of coated Al alloy panels, Corrosion 71 (2015) 771-783.

42. Z. Feng, G.S. Frankel and C.A. Matzdorf, Quantification of accelerated corrosion testing of coated AA7075-T6, J. Electrochem. Soc. 161 (2014) C42-C49.

43. M. Rumyantsev, A. Shauly, S. G. Yiantsios, D. Hasson, A. J. Karabelas and R. Semiat, Parameters affecting the response of dynamic membranes formed by $\mathrm{Zr}$ hydroxide colloids. Desalination 131 (2000) 189-200.

44. G. A. Carter, R. D. Hart, M. R. Rowles, C. E. Buckley and M. I. Ogden, The effect of processing parameters on particle size in an ammonia-induced precipitation of zirconyl chloride under industrial relevant conditions, Powder Technol. 191 (2009) 218-226.

45. J. Qi and G. E. Thompson, Comparative studies of thin film growth on aluminum by AFM, TEM and GDOES characterizaton. Appl. Sur. Sci. 377 (2016) 109-120.

46. J. D. Ramsey and R. L. McCreery, In situ Raman microscopy of chromate effects on corrosion pits in aluminum alloy, J. Electrochem. Soc. 146 (1999) 4076-4081.

47. E. Akiyma, A. J. Markworth, J. K. McCoy. G. S. Frankel, L. Xia and R. L. McCreery, Storage and release of soluble hexavalent chromium from chromate conversion coatings on $\mathrm{Al}$ alloys: kinetics of release. J. Electrochem. Soc. 150 (2003) B83-B91. 
48. J. E. Maslar, W. S. Hurst, W. J. Bowers Jr., H. Hendricks, M. I. Aquino and I. Levin, In situ Raman spectroscopic investigation of chromium surfaces under hydrothermal conditions, Appl. Surf. Sci. 180 (2001) 102-118

49. J. D. Ramsey and R. L. McCreery, Raman microscopy of chromate interactions with corroding aluminum alloy 2024-T3, Corros. Sci. 46 (2004) 1729-1739. 